\title{
Tidal pumping and nutrient fluxes on Georges Bank: A process-oriented modeling study
}

\author{
Song Hu ${ }^{\mathrm{a}, *}$, David W. Townsend ${ }^{\mathrm{b}}$, Changsheng Chen ${ }^{\mathrm{a}}$, Geoffrey Cowles ${ }^{\mathrm{a}}$, Robert C. Beardsley ${ }^{\mathrm{c}}$, \\ Rubao Ji ${ }^{\mathrm{d}}$, Robert W. Houghton ${ }^{\mathrm{e}}$ \\ a University of Massachusetts Dartmouth, Department of Fisheries Oceanography, School for Marine Science and Technology, 706 South Rodney French Boulevard, \\ New Bedford, MA 02744, United States \\ ${ }^{\mathrm{b}}$ University of Maine, School of Marine Sciences, 5706 Aubert Hall, Orono, ME 04469, United States \\ c Department of Physical Oceanography, Woods Hole Oceanographic Institution, Woods Hole, MA 02548, United States \\ d Department of Biology, Woods Hole Oceanographic Institution, Woods Hole, MA 02548, United States \\ e Columbia University, Lamont Doherty Earth Observatory, Palisades, NY 10964, United States
}

\section{A R T I C L E I N F O}

\section{Article history:}

Received 8 October 2007

Received in revised form 3 April 2008

Accepted 10 April 2008

Available online 27 April 2008

\section{Keywords:}

Tidal pumping

Georges Bank

Gulf of Maine

Nutrient flux

FVCOM

\begin{abstract}
A B S T R A C T
Process-oriented studies with the unstructured-grid, three-dimensional Finite-Volume Coastal Ocean Model (FVCOM) of Georges Bank were used to examine the importance of physical processes on the cross-isobath transport of nutrients onto the Bank. Starting from idealized vertical profiles of $\mathrm{NO}_{3}$ constructed from summertime climatologic fields, the nutrient field was integrated in time using a conservative tracer equation with both homogenous and stratified initial hydrography and both tide and wind forcing. The model results reveal that: a) nutrient fluxes are spatially inhomogeneous, with the greatest nutrient flux generated by tidal pumping into surface waters along the edge of the Bank's northern flank; b) a surface nutrient maximum occurs on the northeast flank as a result of advection along the northern edge and bifurcation of the flow as waters circulate clockwise and spread laterally around the eastern portion of the Bank; c) advection enriches nutrient concentrations downstream and around the Bank, generating a donut-shaped pattern of elevated nutrients; and d) waters on the top of the Bank, especially in the southwest portions, experience the lowest nutrient flux rates. The length of time required to reach a quasi-equilibrium state of nutrient distribution over the Bank is controlled primarily by tidal advection, with cross-frontal fluxes modulated by stratification, surface wind stress, and the initial nutrient concentration in the Gulf of Maine source waters. Published by Elsevier B.V.
\end{abstract}

\section{Introduction}

Georges Bank (GB) is a shallow submarine feature located at the opening of the Gulf of Maine, a semi-enclosed continental shelf sea in the northwest Atlantic Ocean (Fig. 1). The Bank is well known for its high biological productivity, which for centuries has supported important commercial fisheries (Backus, 1987); rates of primary production reported for the Bank are thought to be among the highest of any continental shelf sea, exceeding $400 \mathrm{gC} \mathrm{m}^{-2} \mathrm{y}^{-1}$ in the central, shallowest portions of the Bank (O'Reilly et al., 1987).

\footnotetext{
* Corresponding author.

E-mail address: g_shu@umassd.edu (S. Hu).
}

An important driver of the biological productivity of the Bank is its physical oceanographic processes, which are closely tied to its geomorphology. The Bank is a relatively large feature, measuring about $150 \mathrm{~km}$ by $200 \mathrm{~km}$, with an area of about $34,000 \mathrm{~km}^{2}$ shallower than $100 \mathrm{~m}$. Tidal currents, which are most pronounced over the top of the Bank with the dominant constituent being the semi-diurnal M2 with the maximum currents of $\sim 100 \mathrm{~cm} / \mathrm{s}$ (Brown and Moody, 1987), are the dominant physical process. Mixing generated by such strong currents produces a vertically wellmixed water column in the crest area bounded by the $40-$ $50 \mathrm{~m}$ isobath throughout the year. The general pattern of residual currents in the GB region has been known since Bigelow (1927), who first described it as a general clockwise 


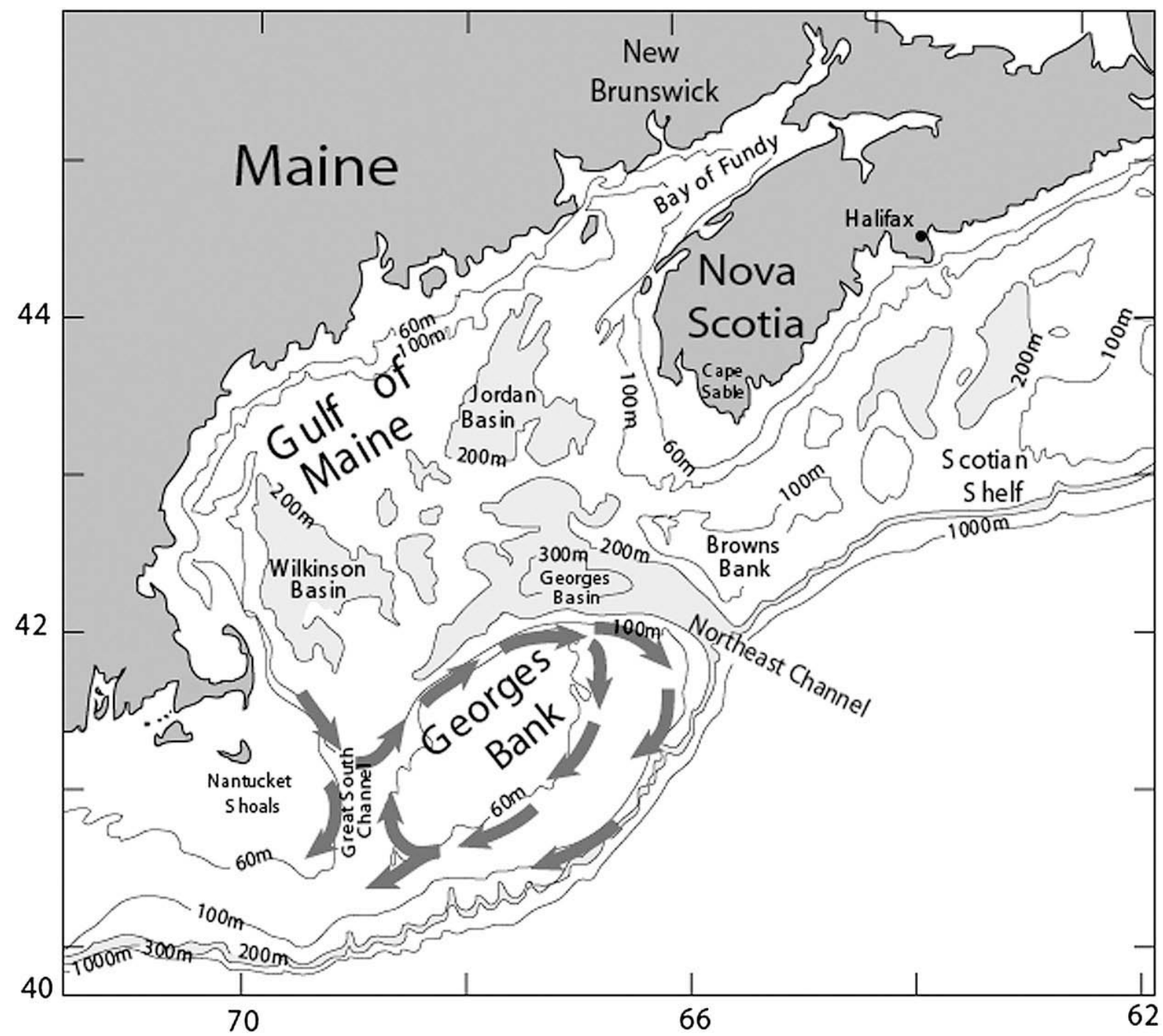

Fig. 1. Bathymetry (in meters) of the Gulf of Maine/Georges Bank region. Heavy arrows indicate the general pathways of water flowing around Georges Bank.

(anticyclonic) flow around the Bank. Later investigators added greater detail to Bigelow's description (Loder, 1980; Butman et al., 1982; Butman and Beardsley, 1987; Naimie et al., 1994; Chen et al., 1995; Limeburner and Beardsley, 1996; Naimie 1996; Chen et al., 2001, 2003a), especially the tidally rectified current "jet" along the steep northern flank.

Generally speaking, the Bank's high biological productivity results because: (1) the Bank is sufficiently shallow that lightlimitation of phytoplankton is unimportant throughout most, or all, of the year; (2) the Bank is surrounded by deep waters rich in dissolved inorganic nutrients, which are available for mixing with Bank waters; and (3) vigorous tidal mixing on the Bank's shoals promotes the injection of those deep water nutrients onto the Bank where their subsequent dispersion and advection drive the Bank's biological oceanography (Townsend et al., 2006). It is this flux of nutrients across the Bank's edges that determines the level of biological production (Riley, 1941; Cohen et al., 1982; Horne et al., 1989; Franks and Chen, 1996; Townsend and Pettigrew, 1997; Franks and Chen, 2001; Townsend et al., 2006; and others). Nutrient fluxes occur around the periphery of the Bank, but they are greatest on the northern half (Pastuszak et al., 1982; Townsend and Pettigrew, 1997) where the bathymetry is steepest and where nutrient-rich slope water resides nearby, having entered Georges Basin from offshore via the Northeast Channel.

The production cycle is highly seasonal in nature and exhibits a pronounced late winter-early spring phytoplankton bloom (Riley, 1941; Walsh et al., 1987; Cura, 1987; Townsend and Pettigrew, 1997; Townsend and Thomas, 2001, 2002). Pre-bloom conditions are established during the fall and winter, when nutrients accumulate and phytoplankton production slows as a result of light-limitation, cooling water temperature, and the breakdown of tidal mixing fronts on the flanks of the Bank. While the exact timing and dynamics are not well known, it appears that seasonal nutrient recharge to the top of the Bank is accomplished more so during the fall months than during the winter (Pastuszak et al., 1982), setting the stage for the winter-spring phytoplankton bloom which begins in December and January (Townsend and Thomas, 2001, 2002). 
Townsend et al. (2006) proposed the following hypothesis for the GB planktonic ecosystem based on earlier observations. Following the winter-spring phytoplankton bloom, a greater cross-frontal nutrient flux on the northern edge of the Bank leads to higher phytoplankton biomass accumulations on the northern flank and the northeast flank. Those cells and nutrients are further advected clockwise around the Bank to the southern flank, fueling secondary production and leading to higher standing stocks of zooplankton in that region. The result is a "donut-like" band of elevated phytoplankton production, being greatest on the northeast flank, and corresponding to the magnitude of new nutrient fluxes (Townsend and Pettigrew, 1997; Townsend et al., 2006). Because that "donut" of primary production is driven by newly injected deep water nutrients, it is "new" production (Dugdale and Goering, 1967; Eppley and Peterson, 1979). This hypothesis is supported by measurements of high $f$-ratios $(\sim 0.7)$ in the tidal mixing front along the northern flank, and much lower ratios $(0.1-0.2)$ in the mixed regions inside the fronts (Loder and Platt 1985). The $f$-ratio defined here is the ratio of new primary production (fueled by the nitrate fluxes) to the total primary production (Eppley and Peterson, 1979).

The significance here is that it is the donut band of "new" primary production, resulting from new nutrient injections, that is available for transfer to higher trophic level biomass such as zooplankton and fish (Townsend and Pettigrew, 1997), and thus it is important to understand in greater detail the nature of nutrient fluxes to the Bank. Conversely, primary production on the top of the Bank, inside the $60-\mathrm{m}$ isobath, is much more dependent (80-90\%) on recycled nitrogenous nutrients. These details, however, have not been well studied. In particular, important aspects of cross-isobath (or crossfrontal) nutrient fluxes onto the Bank, such as the magnitude of these fluxes, their spatial patterns throughout the Bank region, and the major physical mechanism(s) driving these fluxes, are poorly understood.

Dye tracer experiments reported by Houghton and Ho (2001) provided a quantitative measurement of an on-Bank diapycnal Lagrangian flow, revealing 68\% greater crossisobath flow on the northern flank $(\sim 3.2 \mathrm{~cm} / \mathrm{s})$ than the more gently-sloping southern flank $(\sim 1.9 \mathrm{~cm} / \mathrm{s})$. Based on buoyancy measurements and defining "tidal pumping" as a Lagrangian upwelling resulted from the interaction of tidal currents over steep bottom topography (Chen and Beardsley, 1998; Ullman et al., 2003), Ullman et al. (2003) found that the magnitude of the tidal pumping flux on GB was of the same order as the divergent component of the skew flux defined by Loder and Horne (1991) with consideration of the contribution of tidal current variation to the tracer flux through a transect at a fixed location on the northern flank of the Bank. Using model simulations, Chen and Beardsley (1998) and Pringle and Franks (2001) showed a net cross-Bank flux that can result from asymmetric tidal mixing. Later, Chen and Beardsley (2002) attributed the cross-Bank fluxes to four principle physical mechanisms: 1) strong non-linear interactions; 2) asymmetric tidal mixing; 3) varying wind forcing; and 4) chaotic mixing associated with cross-frontal water exchange. All these previous studies were focused on physical mechanisms. Several three-dimensional coupled physical and biological model experiments have been conducted to examine the phytoplankton bloom on the Bank (Franks and
Chen, 1996, 2001; Lewis et al., 2001; Ji et al., 2006a,b; Tian and Chen, 2006), but few efforts have been made to quantify the relative importance of physical versus biological processes in the establishment of the three-dimensional spatial patterns of nutrient fluxes on the Bank.

The purpose of our study reported here was to learn more about the nature of nutrient fluxes across sloping topography and tidal mixing fronts, and the significance of spatial inhomogeneity in those fluxes. Process-oriented model experiments were made to identify 1 ) the primary source and spatial variability of tidal pumping- and wind-induced nutrient fluxes onto the Bank, and 2) the relative influence of tides and winds on on-Bank nutrient pumping under wellmixed and stratified conditions and on nutrient recharge during the seasonal transition from summer to winter.

\section{Numerical model and experiment design}

The numerical experiments were made using the prognostic free-surface, three-dimensional primitive equation unstructured-grid, Finite-Volume Coastal Ocean Model (FVCOM) (Chen et al., 2003b, 2006, 2007). The model incorporates the Mellor and Yamada Level 2.5 turbulent closure scheme (Mellor and Yamada, 1982; Galperin et al., 1988). An unstructured triangular grid was used in the horizontal and a sigma-coordinate in the vertical. A detailed description of FVCOM is given in Chen et al. (2006).

The nutrient concentration is treated as a tracer quantity governed by the following conservation equation:

$$
\begin{aligned}
\frac{\partial N}{\partial t}+u \frac{\partial N}{\partial x}+v \frac{\partial N}{\partial y}+w \frac{\partial N}{\partial z}= & \frac{\partial N}{\partial x}\left(A_{\mathrm{h}} \frac{\partial N}{\partial x}\right)+\frac{\partial N}{\partial y}\left(A_{\mathrm{h}} \frac{\partial N}{\partial y}\right) \\
& +\frac{\partial N}{\partial z}\left(A_{z} \frac{\partial N}{\partial z}\right)
\end{aligned}
$$

where $N$ is the concentration of the nutrient; $u, v$, and $w$ the Cartesian $(x, y, z)$ components of the fluid velocity; $A_{z}$ is the vertical eddy diffusivity calculated using the MY-2.5 turbulent closure scheme; $A_{\mathrm{h}}$ is the horizontal eddy diffusivity computed using the Smagorinsky eddy parameterization method (Smagorinsky, 1963) defined as

$A_{\mathrm{h}}=\frac{0.5 C \Omega^{u}}{\operatorname{Pr}} \sqrt{\left(\frac{\partial u}{\partial x}\right)^{2}+0.5\left(\frac{\partial v}{\partial x}+\frac{\partial u}{\partial y}\right)^{2}+\left(\frac{\partial v}{\partial y}\right)^{2}}$

where $C$ is a constant parameter and $\Omega^{u}$ is the area of the individual momentum control element. $\mathrm{Pr}$ is the Prandtl number. In this study, $C=0.4$ and $P r=1$, which gives reasonable values of $A_{\mathrm{h}}$ ranging from 30 to $500 \mathrm{~m}^{2} / \mathrm{s}$ on Georges Bank.

For this work, deep water nitrate measurements were used to supply the initial conditions in several of the numerical experiments, and the on-Bank flux estimates of nitrate made in several observational programs were used for comparison with model fluxes. Thus, while the evolution of the tracer equation is driven by dynamics not specific to any nutrient, we will consider the nutrient field here to represent nitrate. We excluded biological processes in the model runs in order to isolate the importance of physical processes on the on-Bank nutrient fluxes.

The computational domain encompassed the Gulf of Maine (GoM)/GB region, with the Scotian Shelf to the 
northeast and the New England Shelf at the southwest boundary (Fig. 2). The domain was tessellated by an unstructured triangular grid with a horizontal resolution varying from $\sim 0.5-1.0 \mathrm{~km}$ in the tidal mixing front on GB to $\sim 10 \mathrm{~km}$ near the open boundary. For the vertical discretization, the domain was divided into 31 sigma levels, providing a resolution ranging from $\sim 1.5 \mathrm{~m}$ over the top of the Bank to $10 \mathrm{~m}$ offshore of the continental shelf where the bathymetry was truncated to $300 \mathrm{~m}$. The bathymetry was interpolated directly from the most current USGS bathymetric database (Roworth and Signell, 2001). The external and internal time steps were 8.94 and $89.4 \mathrm{~s}$, respectively, which results in a nearly integral number of time steps in a $\mathrm{M}_{2}$ period. The model was driven by $\mathrm{M}_{2}$ tidal forcing at the open boundary. For model runs of process studies that included surface forcing, wind forcing were added after the tidal flow reached equilibrium state. The initial conditions for temperature $(T)$ and salinity $(S)$ were specified using monthly or bi-monthly climatologic $T / S$ fields generated by the FVCOM development team at UMASSD. The initial condition for nutrient concentration $N$ was assumed to be horizontally uniform and ver- tically varying, with a case-dependent profile specified for a given case.

To identify the importance of various physical processes to the on-Bank nutrient flux, the following six model experiments were conducted:

\subsection{Experiment \#1}

The model was driven solely by tidal forcing with homogeneous (uniform density) hydrography $\left(T=20{ }^{\circ} \mathrm{C}\right.$, $S=30$ ). The initial nutrient concentration $N_{0}$, set as our Type I condition (Fig. 3a), was assumed to be uniform in the horizontal, and to be zero from the surface to $60-\mathrm{m}$ depth, linearly increasing to $15 \mu \mathrm{M}$ from $60 \mathrm{~m}$ to $80 \mathrm{~m}$, from $15 \mu \mathrm{M}$ to $20 \mu \mathrm{M}$ from $80 \mathrm{~m}$ to $150 \mathrm{~m}$, and constant at $20 \mu \mathrm{M}$ to the bottom. The Type I condition represents the typical nutrient profile in summer. In this case, the absence of nutrients characterized the shallow potion of GB. The purpose of Exp. \#1 was to assess the interaction of tidal currents over steep bottom topography on the on-Bank nutrient transport.

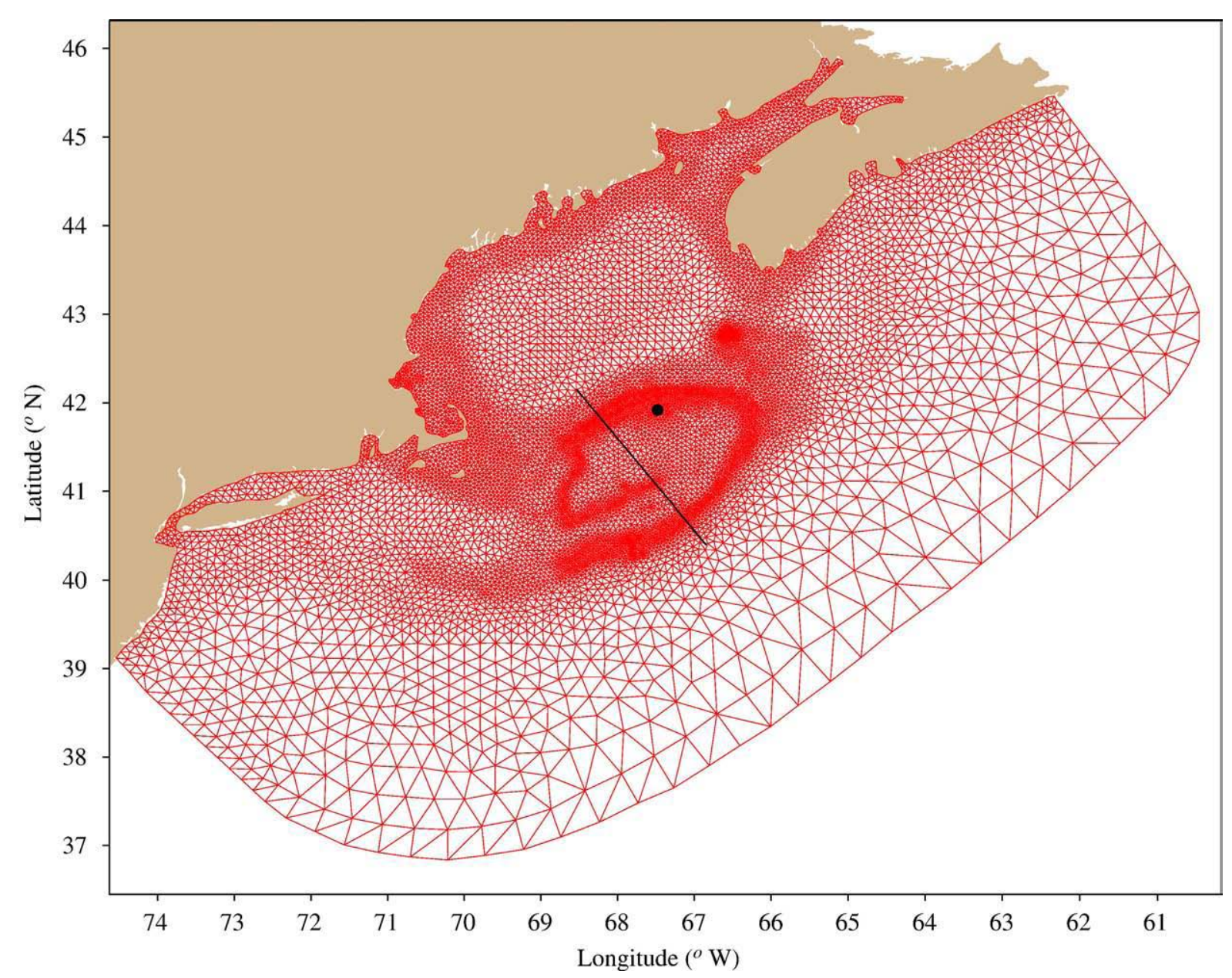

Fig. 2. The FVCOM grid for the Gulf of Maine, Georges Bank, Scotian Shelf, and New England Shelf region. The heavy solid line indicates a section used to present the cross-Bank distribution of temperature, salinity, density and nutrients. The solid circle is the location (Site $\mathrm{A}$ : $67.26^{\circ} \mathrm{W}, 41.98^{\circ} \mathrm{N}, 45 \mathrm{~m}$ water depth) nearby the northeast flank used to show the time series of the nutrient concentration. 

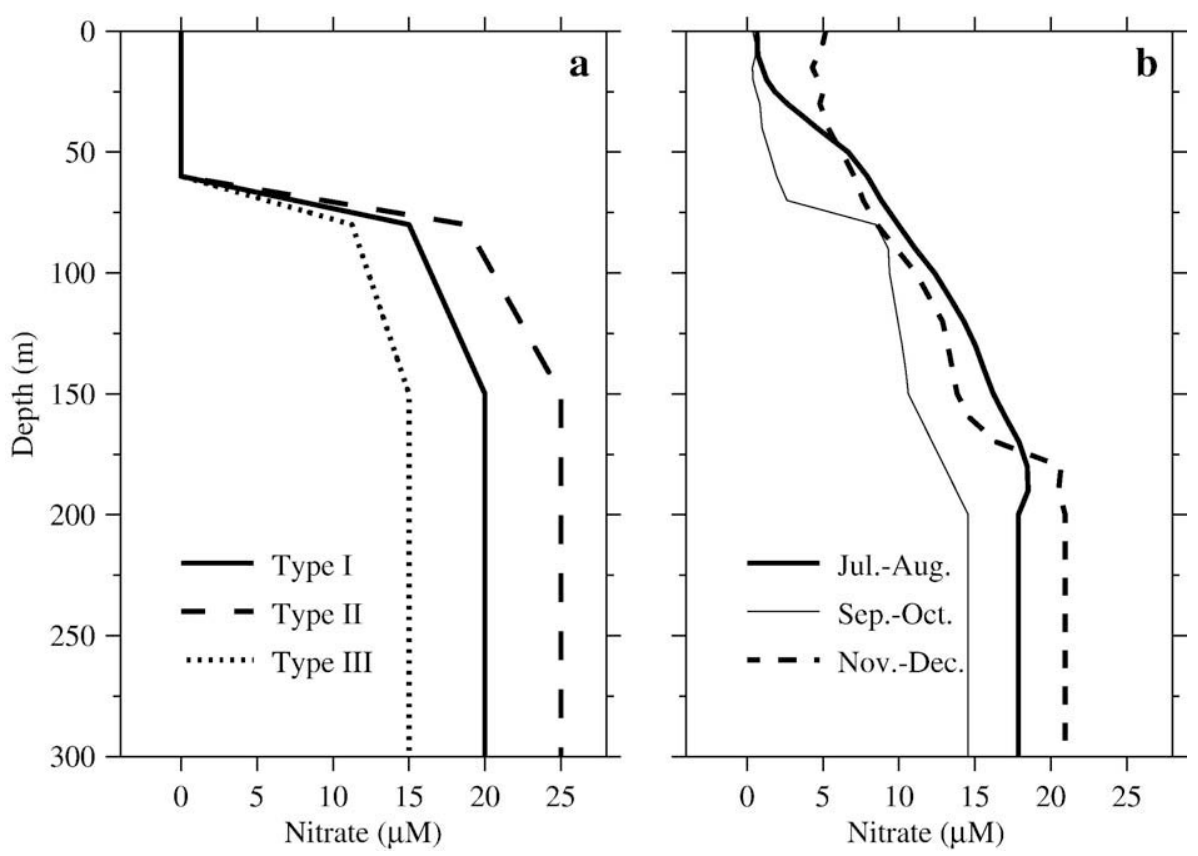

Fig. 3. Panel a: Vertical profiles of initial nutrient concentration. Type I: the profile used for the standard experiment cases (Exp. \#1-Exp. \#3). Type II and Type III: profiles used in Exp. \#5 for higher and lower initial nutrient cases, respectively. Panel b: Vertical profiles of the bi-monthly climatologic-mean nitrate concentration off the northern flank of Georges Bank. These profiles were used for the initial conditions of the nutrient concentration in Exp. \#6. Note: for simplification, the nitrate is set to be constant in the deep region below 200-m depth.

\subsection{Experiment \#2}

For this experiment, the model was driven solely by tidal forcing using a stratified initial hydrography representative of early summer. The initial $T$ and $S$ fields were specified using the monthly averaged climatologic hydrographic data for June (Fig. 4). The initial nutrient condition used in this experiment was the same as that in Exp. \#1 (Type I, Fig. 3a). The purpose of Exp. \#2 was to assess the roles of advection and vertical/ lateral mixing within the tidal mixing front and upwelling at the shelf break front in the on-Bank nutrient flux as the fronts intensified in summer.

\subsection{Experiment \#3}

In this experiment, the model was driven by tidal forcing under stratified hydrographic conditions with a seasonal variation. Model runs were made starting with the initial $T / S$ conditions specified using July-August, September-October, and November-December bi-monthly averaged hydrographic data (Fig. 5), respectively. To examine the impact of this seasonal variation in the initial stratification on the on-Bank nutrient flux, we used the same Type I vertical profile of initial nutrient concentration $N_{0}$ for all three cases. This experiment was designed to examine the influence of stratification on nutrient recharge to the Bank during the seasonal transition from summer to autumn.

\subsection{Experiment \#4}

The model was driven by both tidal and wind forcing using the same stratified initial and seasonally-varying hydrography as Exp. \#3. The wind forcing was the bi-monthly averaged wind stress over GB, which was estimated from a 27-year meteorological model hindcast (Table 1 ). That hindcast was conducted using the GoM meso-scale meteorological model (MM5) (Chen et al., 2005) for 1978-2004, with assimilation of all available buoy measurements. To estimate variations in the nutrient flux due to the temporal fluctuations of wind stress, we also drove the model with inclusion of the wind stress variation determined by the standard deviation calculating from hourly wind stress during each bi-monthly period (Table 2). This experiment was aimed at qualifying and quantifying the relative importance of the wind stress and its variability to tidal pumping on the nutrient recharge during the seasonal transition from summer to autumn.

\subsection{Experiment \#5}

The model was driven solely by tidal forcing with various initial nutrient concentration profiles but with the same early summer stratified initial hydrography used in Exp. \#2. The historical nutrient data available for the GoM region exhibit significant temporal and spatial variations in vertical concentration profiles which can directly alter the net nutrient flux onto GB in our model runs. By using higher (Type II) and lower (Type III) initial nutrient concentrations relative to our baseline (Type I), we were able to examine the sensitivity of the net on-Bank nutrient flux to the variability in the initial nutrient distribution (Fig. 3a).

\subsection{Experiment \#6}

The model was driven by both tidal forcing and seasonal mean wind stress with stratified initial hydrography as done in Exp. \#4. The difference is that in this experiment the initial 

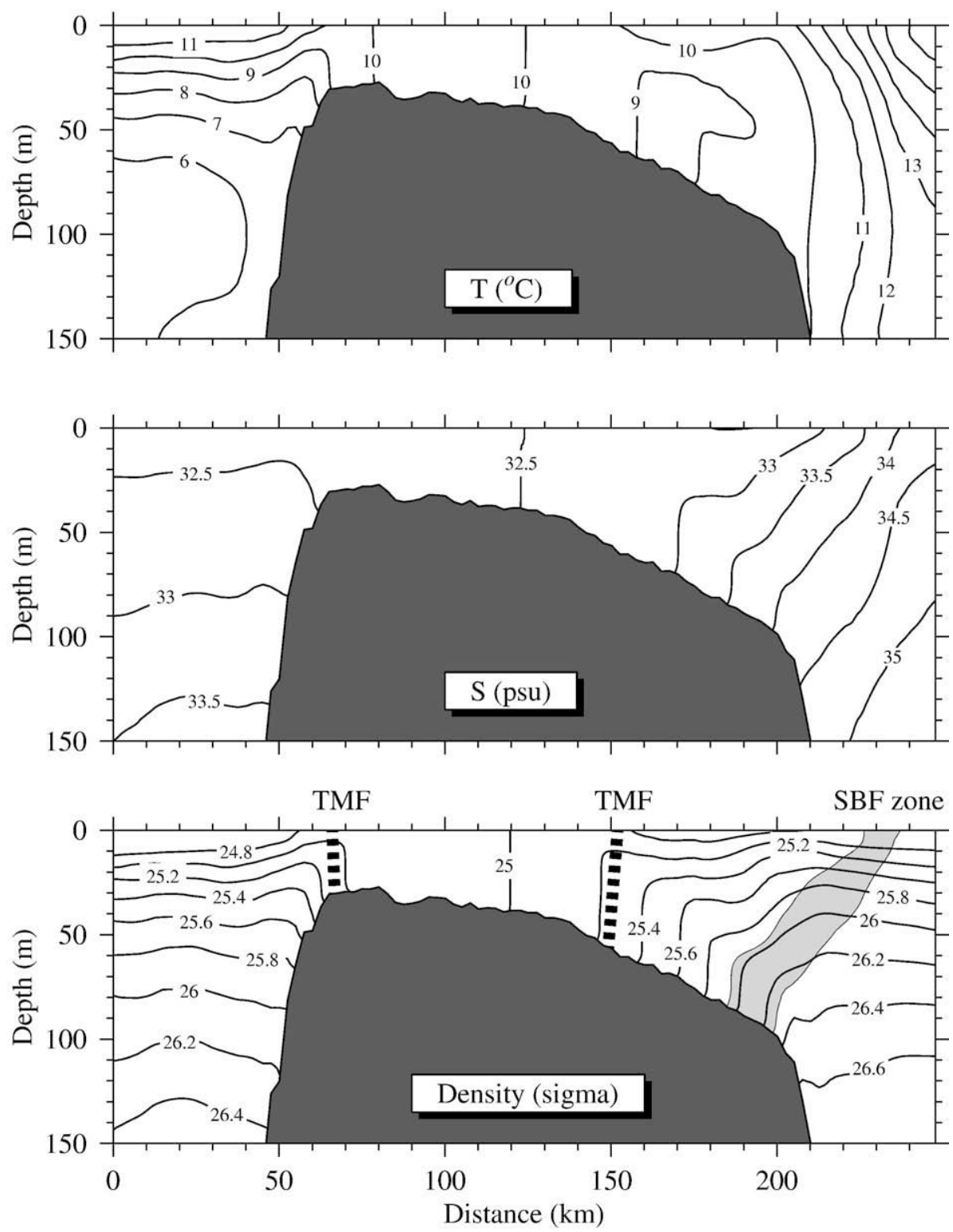

Fig. 4. Cross-bank distributions of temperature, salinity and density fields used for the initial hydrographic conditions in Exp. \#2. Heavy dashed lines are locations of the tidal mixing front (TMF) and shaded area is the location of the shelf break front (SBF) zone defined by the salinity gradient.

nutrient conditions are specified laterally homogeneously using the seasonal mean nutrient profile constructed from historical nitrate data collected in the deep waters off the northern flank of GB (Fig. 3b). This experiment was aimed at estimating the seasonal variation of the on-Bank nutrient flux using a more realistic seasonal mean condition for nitrate.

One of the key metrics necessary for our analysis is the estimation of the cross-frontal nutrient flux over GB. In a system such as this, characterized by strong tidal currents and a large tidal excursion scale, the Lagrangian movement of the nutrient parcel over a tidal cycle must be taken into account when the flux is calculated. One method to do so is to use the skew flux algorithm proposed by Loder and Horne (1991). Here we take a simpler approach: the initial nutrient concentration was set to zero in the shallow area bounded by the $60-\mathrm{m}$ isobath over $\mathrm{GB}$. If the $60-\mathrm{m}$ isobath is defined as the boundary for the estimation of the on-Bank nutrient flux, any nutrients appearing inside this region are new, and thus the tidally-averaged mean nutrient concentration in the $60-\mathrm{m}$ enclosed area can be calculated discretely using

$\bar{N}_{T}=\frac{1}{T} \sum_{k=1}^{n} \bar{N} \Delta t=\frac{1}{T} \sum_{k=1}^{n}\left[\frac{\sum_{i=1}^{m} \bar{N}_{i}\left(H_{i}+\zeta_{i}\right) S_{i}}{\sum_{i=1}^{m}\left(H_{i}+\zeta_{i}\right) S_{i}}\right] \Delta t$

where $\bar{N}$ is the mean nutrient concentration within the area bounded by the $60-\mathrm{m}$ isobath; $S_{i}$ is the control area of each node; $\bar{N}_{i}, H_{i}$, and $\zeta_{i}$ are the vertically-averaged nutrient concentration, the mean water depth, and the surface elevation at 

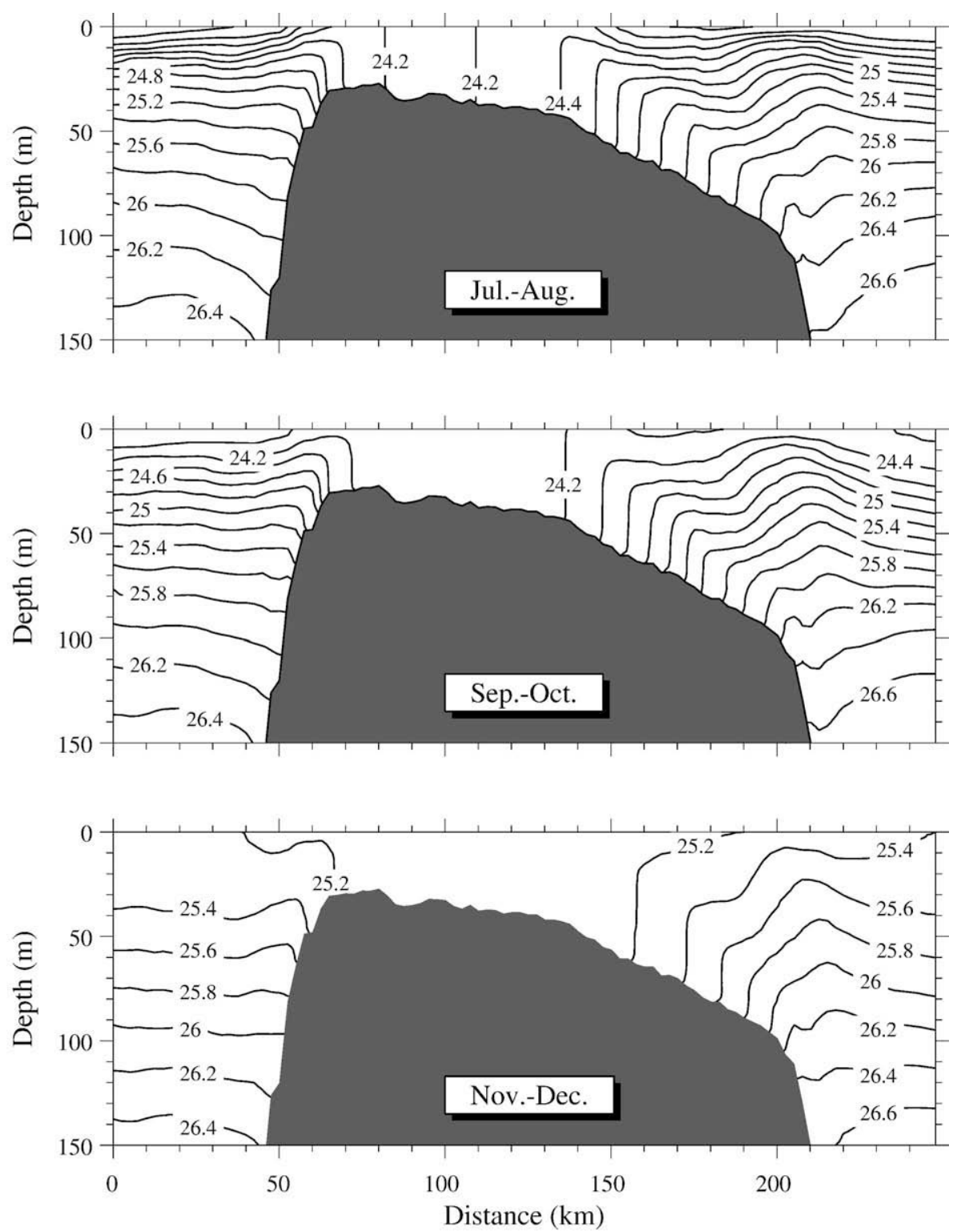

Fig. 5. Cross-bank distributions of the bi-monthly density field used for the initial conditions in Exp. \#3, \#4 and \#6. Upper: July-August. Middle: SeptemberOctober. Bottom: November-December.

each node, respectively; $T$ is the period of the $\mathrm{M}_{2}$ tide; $m$ is the total number of elements in the area bounded by the $60-\mathrm{m}$ isobath; and $n$ is the total number of time steps over a $\mathrm{M}_{2}$ tidal cycle.

\section{Model results}

\subsection{Experiment \#1}

Driven solely by the $\mathrm{M}_{2}$ tidal forcing at open boundaries, the tidal and residual currents and the surface elevation reached an equilibrium state after ten tidal cycles. The nutrient tracer equation was activated at the 20th tidal cycle from an initial nutrient condition based on the Type I profile and then integrated for an additional 80 tidal cycles. In this case with zero stratification, the residual currents over GB are characterized by a clockwise circulation gyre, with a strong current jet of $\sim 19 \mathrm{~cm} / \mathrm{s}$ along the northern and northeastern flanks and a weak return flow of $\sim 3-8 \mathrm{~cm} / \mathrm{s}$ on the crest and southern flank (Fig. 6a). The residual current jet bifurcates at

Table 1

Bi-monthly wind ellipses for Georges Bank

Jul-Aug Sep-Oct


Table 2

Wind stress statistics for Georges Bank

\begin{tabular}{|c|c|c|c|c|}
\hline \multirow[t]{2}{*}{ Month } & \multirow{2}{*}{$\begin{array}{l}\text { Eastward stress } \\
\left(\mathrm{N} / \mathrm{m}^{2}\right) \\
\text { Mean } \pm \text { Std }\end{array}$} & \multirow{2}{*}{$\begin{array}{l}\text { Northward stress } \\
\left(\mathrm{N} / \mathrm{m}^{2}\right) \\
\text { Mean } \pm \text { Std }\end{array}$} & \multicolumn{2}{|c|}{$\begin{array}{l}\text { Large wind stress } \\
(\text { mean }+ \text { Std })\end{array}$} \\
\hline & & & $\begin{array}{l}\text { Magnitude } \\
\left(\mathrm{N} / \mathrm{m}^{2}\right)\end{array}$ & $\begin{array}{l}\text { Direction } \\
(\text { Deg } N)\end{array}$ \\
\hline Jul.-Aug. & $0.012 \pm 0.035$ & $0.011 \pm 0.034$ & 0.065 & 46 \\
\hline Sep.-Oct. & $0.015 \pm 0.075$ & $-0.012 \pm 0.072$ & 0.123 & 133 \\
\hline Nov.-Dec. & $0.061 \pm 0.137$ & $-0.029 \pm 0.110$ & 0.242 & 125 \\
\hline
\end{tabular}

the northeastern flank where the $40-\mathrm{m}, 60-\mathrm{m}$ and $100-\mathrm{m}$ isobaths split. As a result, the on-Bank along-isobath flow (following the $60-\mathrm{m}$ isobath) in that area drops to $\sim 10 \mathrm{~cm} / \mathrm{s}$. Limeburner and Beardsley (1996) found that there exists at least three preferred paths over the eastern flank for nearsurface drifters, perhaps due to the bottom sand ridge. This pattern was also found in other observations of drifters (Naimie et al., 2001; Brink et al., 2003). Our model results indicate that the flow paths over the eastern flank onto the Bank are associated with the location where the isobaths diverge. This flow pattern was reported in Chen et al. (2003a) and is consistent with tidal rectification theory derived by Loder (1980) and previous results predicted by other numerical circulation models (Greenberg, 1983; Lynch and Naimie, 1993; Chen et al., 1995; Chen et al., 2001, Naimie et al., 2001).

The nutrient distribution is controlled by tidally-induced advection and mixing. The model showed that the nutrients in the central crest region of the Bank bounded by the $60-\mathrm{m}$ isobath came primarily from the northern flank, with a major contribution from the current bifurcation area on the northeastern flank. This can be seen clearly in the tidally-averaged nutrient distribution at the 80th tidal cycle with a region of higher nutrient concentration intruding towards the crest area like a tongue originating from the northeastern flank (Fig. 6b-e). Due to the lack of stratification, the nutrient concentration was quickly mixed to the surface by energetic tidal mixing (Fig. 6b-e). The time sequence plots of the nutrient concentration on a cross-Bank transect, Transect-A, show an asymmetric pattern on the northern and southern flanks in the area shallower than $60 \mathrm{~m}$. At the 40th tidal cycle, for example, a value of 1-2 $\mu \mathrm{M}$ was found at the $40-\mathrm{m}$ isobath on the northern flank, while it was located near the 70-m isobath on the southern flank (Fig. 6b,c). At the 80th tidal cycle, the nutrient concentration over most of the northern flank exceeded $2 \mu \mathrm{M}$, while the contours of $1-2 \mu \mathrm{M}$ were still near the 70-m isobath (Fig. 6d). At this time, the mean nutrient concentration on the top of the Bank bounded by the $60-\mathrm{m}$ isobath is $\sim 2.0 \mu \mathrm{M}$ (Fig. 6e).

Two major points are revealed by this model run without stratification: First, the interaction of tidal currents with topography produces a flux of deep water nutrients from the GoM onto the crest of GB. In this case, the on-Bank nutrient flux is predominantly controlled by the on-Bank residual currents in the topographically-driven bifurcation region on the northeast flank. This "tidal pumping" process provides a continuous supply of nutrients. The role of "tidal pumping" in the on-Bank nutrient flux was studied in previous investigations (Franks and Chen, 1996; Chen and Beardsley, 1998; Franks and Chen, 2001; Ullman et al., 2003). The difference here is that this experiment shows that the major source of the pumped nutrients is at the northeast flank where the current bifurcates, in keeping with field observations on nutrient distributions (Pastuzak et al., 1982; Townsend and Pettigrew, 1997; Townsend and Thomas, 2001, 2002). Second, in the absence of vertical stratification, tidal mixing quickly mixes the nutrients throughout the upper water column. This process indirectly accelerates the on-Bank nutrient flux by bring the nutrients to the near-surface layer where the tidal excursion is large and residual currents are strong.

\subsection{Experiment \#2}

The June monthly climatological $T / S$ fields are characterized by two density fronts over GB: 1) the tidal mixing front (TMF), a closed dynamic feature around the crest of GB, located at about the 40-m isobath on the northern flank and between the $50-\mathrm{m}$ and $60-\mathrm{m}$ isobaths on the southern flank; and 2 ) the shelf break front (SBF), located near the $80-\mathrm{m}$ to $100-\mathrm{m}$ isobath on the southern edge of GB. These hydrographic features did not change significantly during the model run driven by the $\mathrm{M}_{2}$ tidal forcing. However, both the TMF and SBF significantly intensified the residual currents around GB, in comparison to Exp. \#1, which had homogenous hydrography. On the northern flank, the current jet increased to $\sim 30 \mathrm{~cm} / \mathrm{s}$, while on the southern flank, a relatively strong along-Bank residual current of $\sim 10-15 \mathrm{~cm} / \mathrm{s}$ appear at the SBF (Fig. 7a). At the bifurcation area on the northeast flank, the on-Bank residual current along the $60-\mathrm{m}$ isobath was about $15 \mathrm{~cm} / \mathrm{s}$ (Fig. 7a), or $\sim 5 \mathrm{~cm} / \mathrm{s}$ greater than that found in Exp. \#1.

Comparing Fig. 6 with Fig. 7, the addition of early summer stratification to the initial hydrography significantly enhanced the on-Bank nutrient flux but did not change the spatial structure of the tidal pumping onto GB. The model clearly showed that the nutrient flux onto the crest area of GB originated from the northern flank, with a major contribution delivered by the current bifurcation on the northeast flank (Fig. 7a). At the 40th tidal cycle, a nutrient patch appeared along the northern flank, with a maximum value of $\sim 4.6 \mu \mathrm{M}$ in the region of the current bifurcation separation on the northeast flank. This patch extended along the 60-m isobath and toward the top of GB (Fig. 7b,c). At the 80th tidal cycle, higher nutrient levels extended over $50 \%$ of the shallow area bounded by the $60-\mathrm{m}$ isobath (Fig. $7 \mathrm{~d}, \mathrm{e}$ ), and the maximum value on the northeast flank reached $\sim 5.7 \mu \mathrm{M}$.

Stratification suppressed tidal mixing in the deep region off the flanks of GB. As a result, the tidal pumping of nutrients was restricted to the near-bottom regions of the slope, with a maximum on-Bank flux at the top of the sloping boundary layer (Fig. 7c, e). On the northern flank, the nutrients were pumped toward the upper water column of the tidal frontal zone, while on the southern flank the major pumping occurred within the shelf break frontal zone. In this case, the cross-Bank distribution of nutrients on the slope reached an equilibrium state after 20 tidal cycles.

High concentrations of nutrients also appeared in the Nantucket Sound/Nantucket Shoals area as a result of tidal pumping from the Great South Channel (Fig. 7b,d). There were no nutrients specified in the initial conditions in these areas because they are shallower than 60-m. With the early 
42

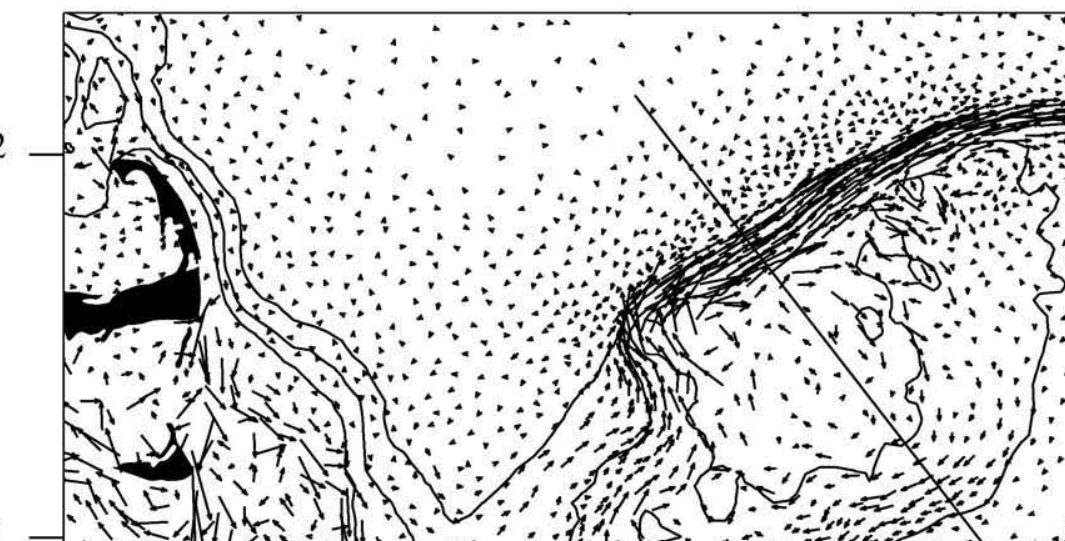

41

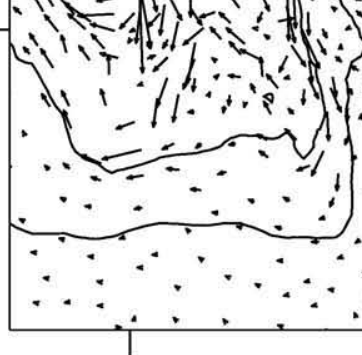

70
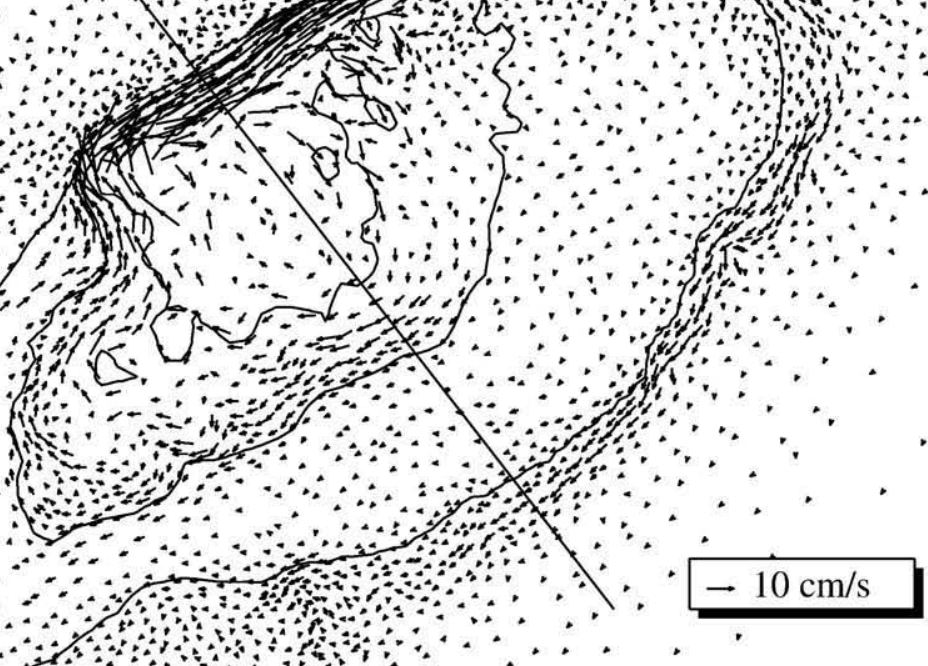

68

67

66

\section{$\mathrm{N}(\mu \mathrm{M})$}
$\begin{array}{llllllll}0 & 1 & 2 & 3 & 4 & 5 & 6 & 7\end{array}$
$40^{\text {th }}$ tidal cycle
b
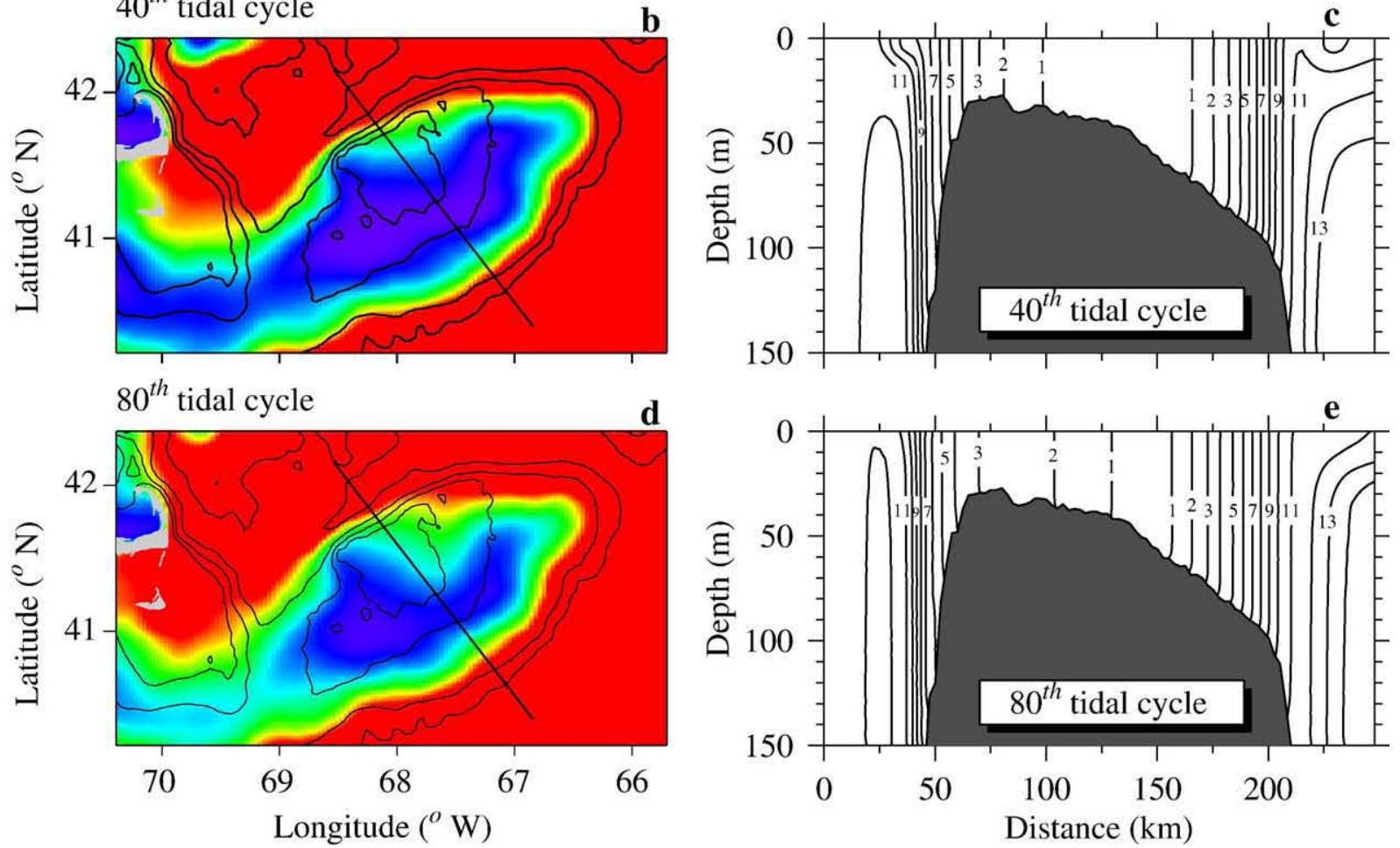

Fig. 6. Horizontal distribution of the near-surface residual current vectors (upper) and near-surface (lower left) and cross-Bank (lower right) distributions of the tidally-averaged nutrient concentration after 40 (upper) and 80 (lower) tidal cycles over Georges Bank for the homogeneous case (Exp. \#1). The 40-, 60-, and $100-\mathrm{m}$ isobaths are shown for reference in the upper and left panels, with the $200-\mathrm{m}$ isobath also shown in the left panels. 


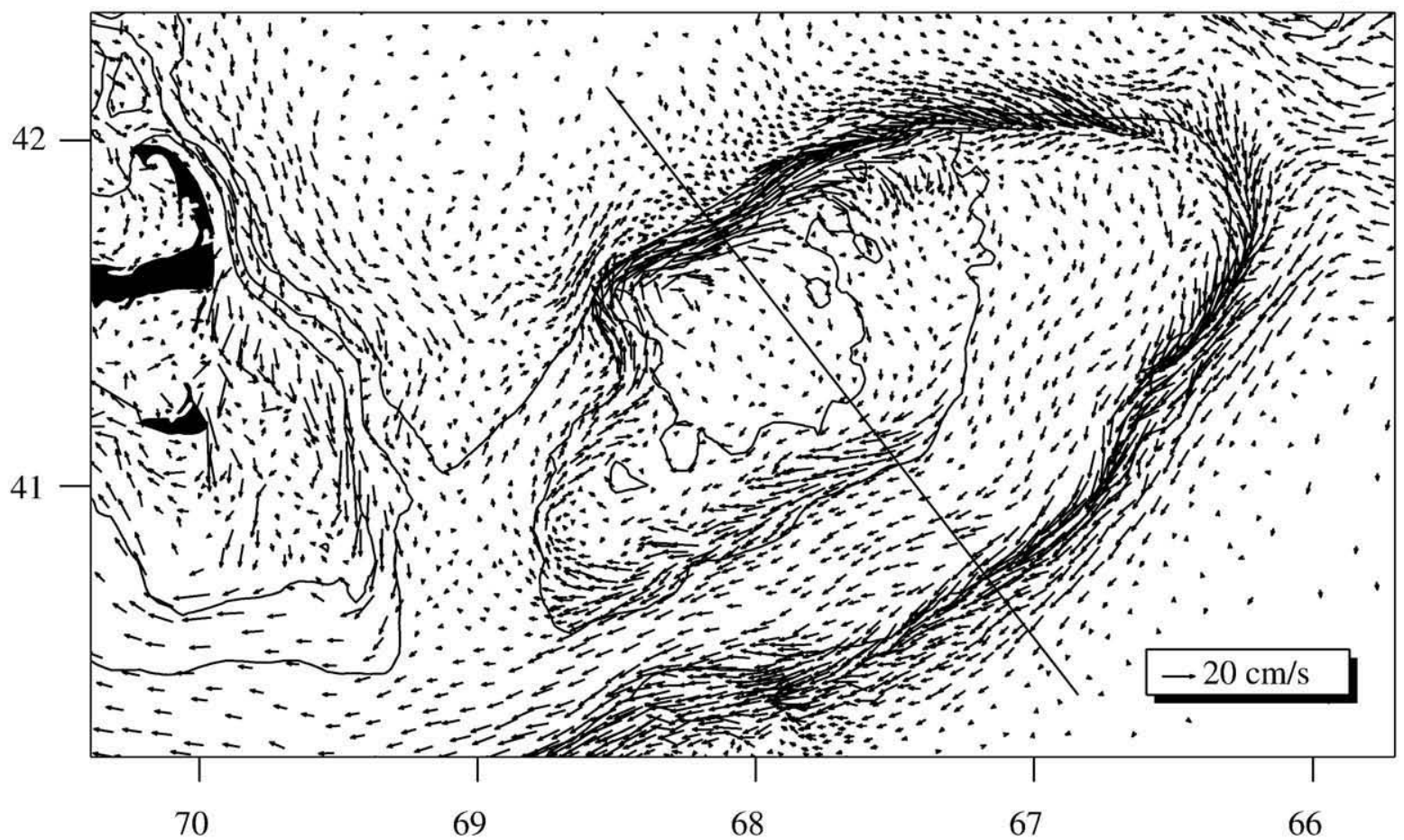

\begin{tabular}{|c|c|c|c|c|}
\hline & 11 & $T$ & $T$ & \\
\hline $\begin{array}{lll}0 & 1 & 2\end{array}$ & 23 & 4 & 5 & 6 \\
\hline
\end{tabular}

$\mathrm{N}(\mu \mathrm{M})$

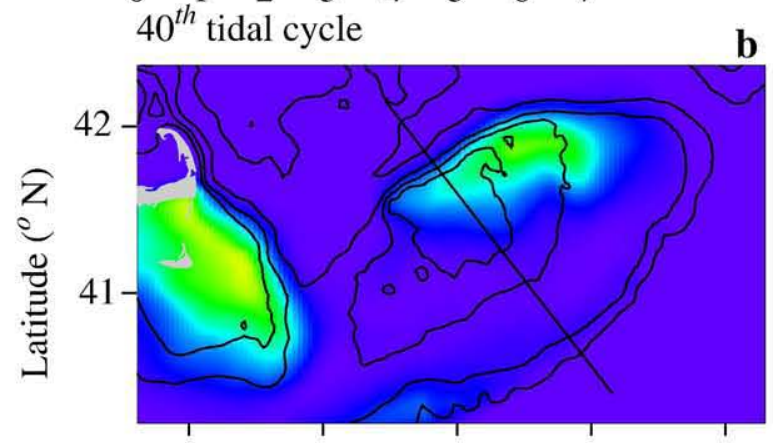

b
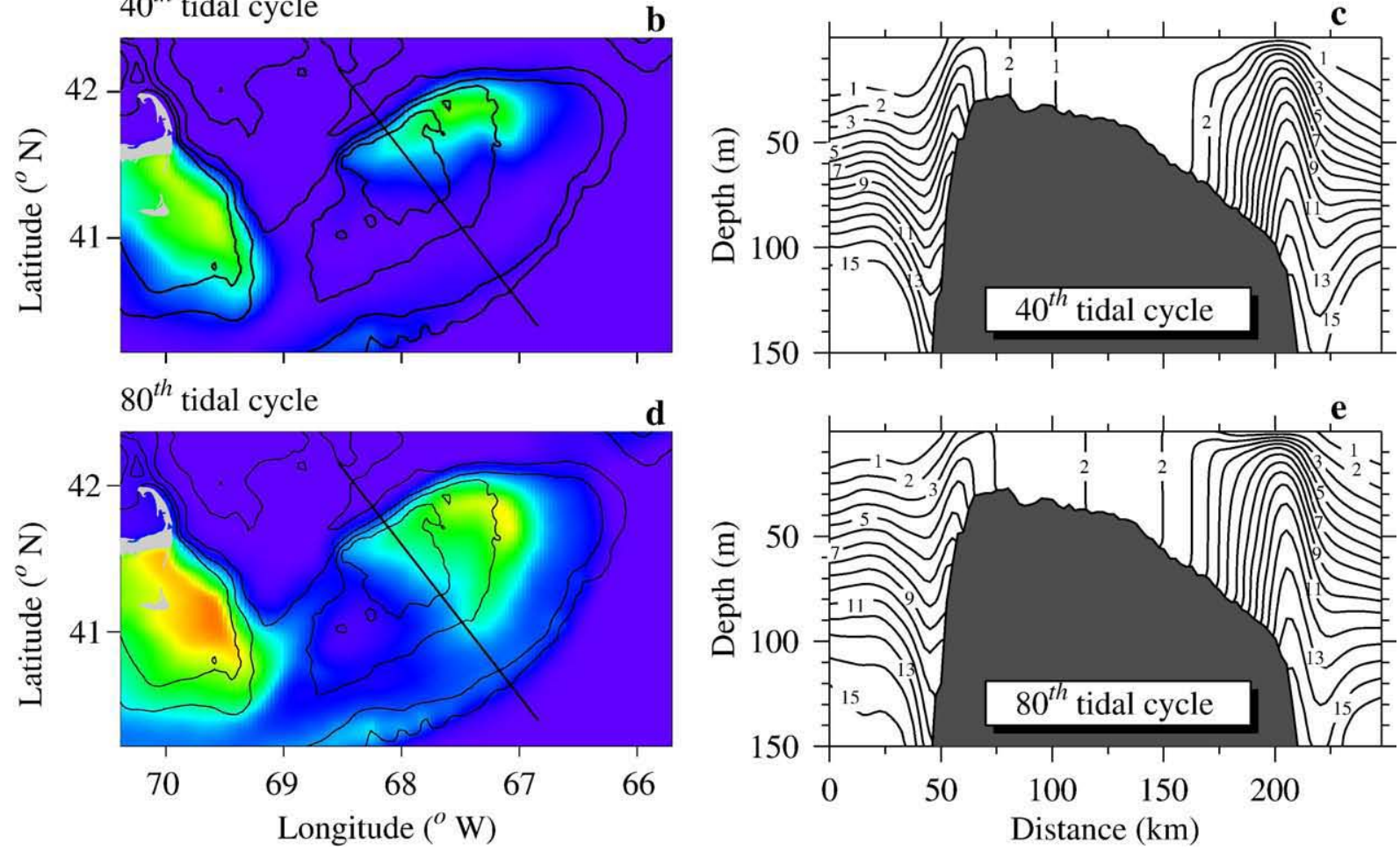

d

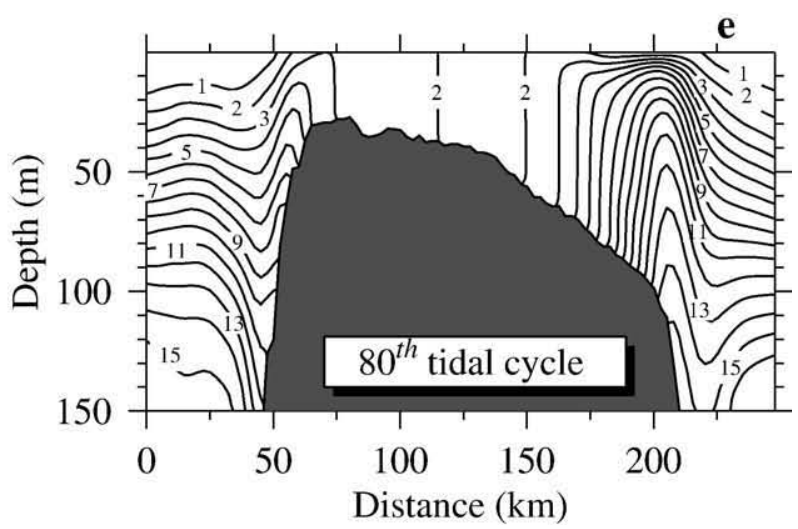

Fig. 7. Horizontal distribution of the near-surface residual current vectors (upper) and near-surface (lower left) and cross-Bank (lower right) distribution of the tidally-averaged nutrient concentration at the 40th and 80th tidal cycles over Georges Bank for the early summer stratification case (Exp. \#2). The 40-, 60-, and $100-\mathrm{m}$ isobaths are shown in the upper and left panels with the $200-\mathrm{m}$ isobath also shown in the left panels. 
summer stratified hydrography, the interaction of tidal currents over topography function like a pump to supply nutrients continuously to these areas. This model result is consistent with both satellite ocean color imagery of sea surface temperature and coupled biological-physical model results, which have shown a high concentration of phytoplankton in this area (Franks and Chen, 2001). It has been known that Nantucket Sound is a flow-through dynamic system that functions as a conveyor to transport waters from Cape Cod and the western GoM to the coastal regions of southern New England. It has been known that Nantucket
Shoals is a region of high phytoplankton biomass. There is a southwest flow on Nantucket Shoals that carries GoM water over the shoals to the south of Nantucket (Limeburner and Beardsley, 1982; Chen et al., 2001). Our experiment indicates that GoM water is the source of nutrients supporting the presumed high productivity.

The tidally-averaged mean nutrient concentration on the crest of the Bank, inside the $60-\mathrm{m}$ isobath, increased linearly with time. The area inside the $60-\mathrm{m}$ isobath is about $1.4 \times 10^{4} \mathrm{~km}^{2}$, so the supply rate of nutrients in Exp. \#2 was $\sim 0.03 \mu \mathrm{mol} \mathrm{N} / \mathrm{m}^{2} / \mathrm{s}$. Townsend and Pettigrew (1997) esti-
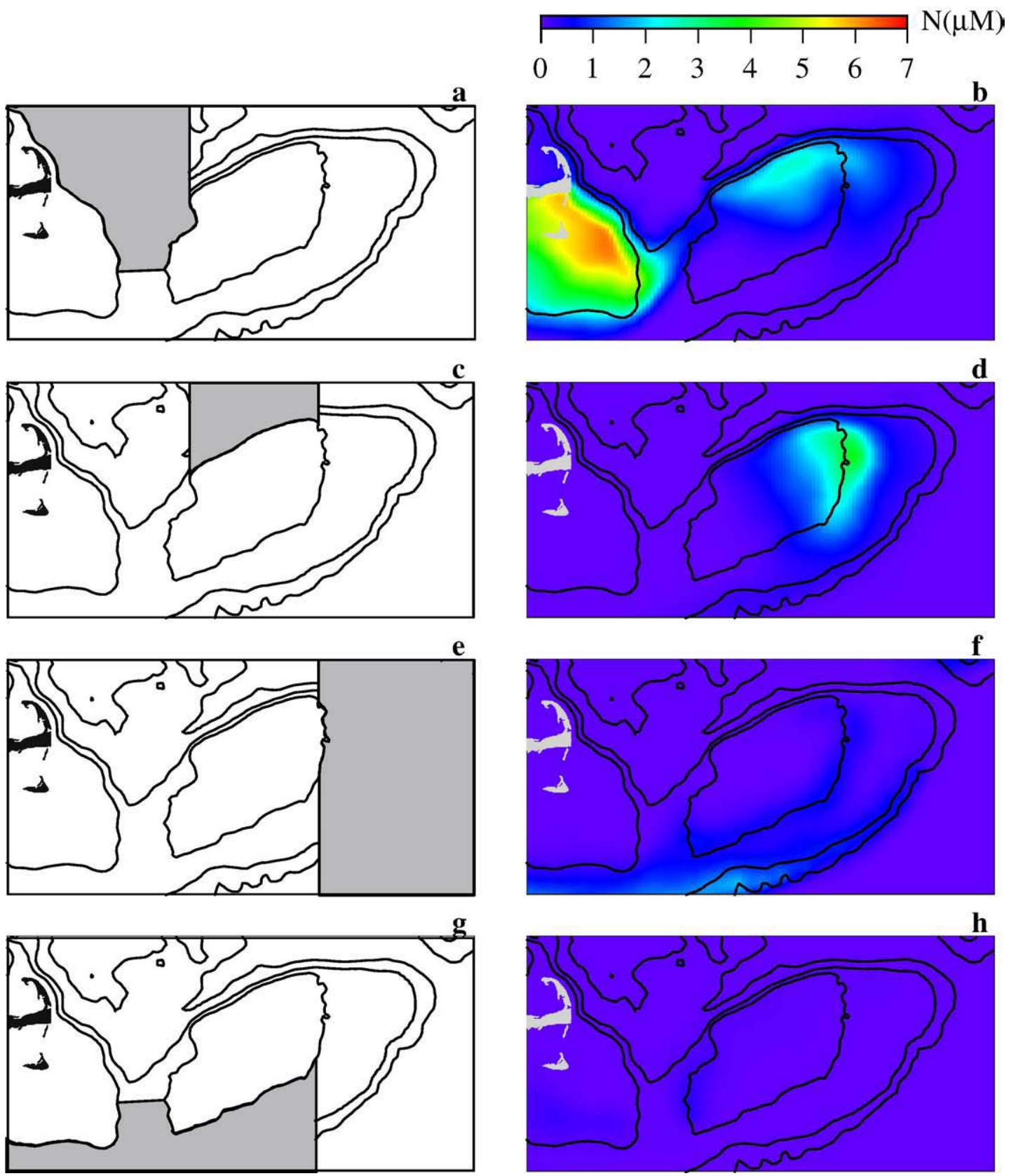

Fig. 8. Four different geographical areas (shown as gray shading) where non-zero initial nutrient concentrations are specified (left panels) and the corresponding tidally-averaged concentrations of the near-surface nutrients at the 80th tidal cycle (right panels). The 60-, 100-, and 200-m isobaths are shown. 


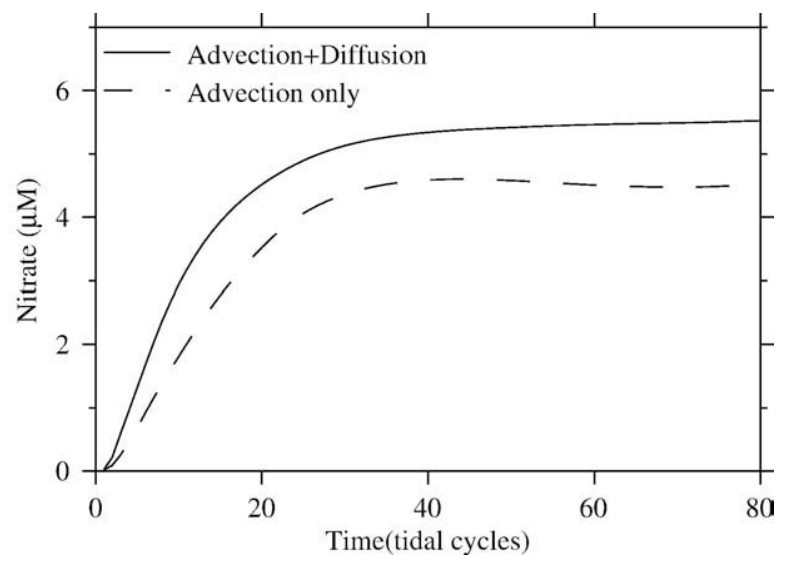

Fig. 9. Time series of the vertically-averaged nutrient concentration at Site A (shown in Fig. 2) on the northeast flank for the cases with (solid line) and without (dashed line) diffusion.

mated a nitrate supply rate onto GB based on field measurements and reported an average rate of $0.034 \mu \mathrm{mol} \mathrm{N} / \mathrm{m}^{2} / \mathrm{s}$, which is very close to these model results. Due to the lack of biological processes in our experiments, we cannot state that tidal pumping supports the entire nutrient supply on $\mathrm{GB}$, but these results do support the idea that tidal pumping is one of the major processes bringing nutrients to the crest of GB.

To identify the point of origin of nutrients in the deep GoM region that were carried onto GB and Nantucket Sound/ Nantucket Shoals, we conducted a series of numerical experiments by specifying non-zero initial nutrient concentration in select regions shown in Fig. 8. The Type I profile (Fig. 3a) was used to specify the vertical nutrient distribution for each case. The right panels of Fig. 8 show the distributions of tidally-averaged near-surface nutrient concentration at the 80th tidal cycle. With nutrients initially only in region I (Fig. 8a), the deep nutrients were predominantly carried into two near-surface regions: one on the northern flank and the other over the Nantucket Sound/Shoals (Fig. 8b). With nutrients emanating from region II (Fig. 8c), near-surface nutrients were only detected on the eastern edge of the tidal mixing front on GB (Fig. 8d). With nutrients emanating from region III (Fig. 8e), most of the nutrients starting on and also pumped onto the eastern flank were moved southward and off the Bank (Fig. 8f). Similar results were found in the case where nutrients were specified as emanating from region IV (Fig. 8g), in which nearly the entire nutrient load was advected southward, and little was detected on the western flank in the vicinity of the $60-\mathrm{m}$ isobath (Fig. 8h). In the region I case, in addition to direct pumping of elevated nutrients to the Nantucket Sound/Nantucket Shoals region, a portion of the nutrients was carried eastward along the local bathymetry to the northern flank and then pumped across much of the Bank. In the region II case, nutrients were advected along the northern flank and then pumped onto GB near the location of the residual current bifurcation on the northeast flank. These experiments clearly show that the deep GoM region off GB, west of the northeast flank, is the major nutrient source supplying GB.

To elucidate the relative contributions of advection and diffusion to nutrient supply on GB, we re-ran Exp. \#2 by turning off both vertical and horizontal diffusion terms in the tracer equation. We compared the time series of the nutrient concentration for the cases with and without diffusion at site A on the northeast flank. The results clearly show that tidal pumping around that area was dominantly driven by advective processes, with a secondary contribution from vertical/horizontal diffusion (Fig. 9).

\subsection{Experiment \#3}

Model runs using initial conditions based on the bimonthly averaged hydrographic fields for July-August, September-October and November-December showed a clear summer-to-winter transition of the tidal mixing front on GB, during which the mixing region enlarged as the front moved

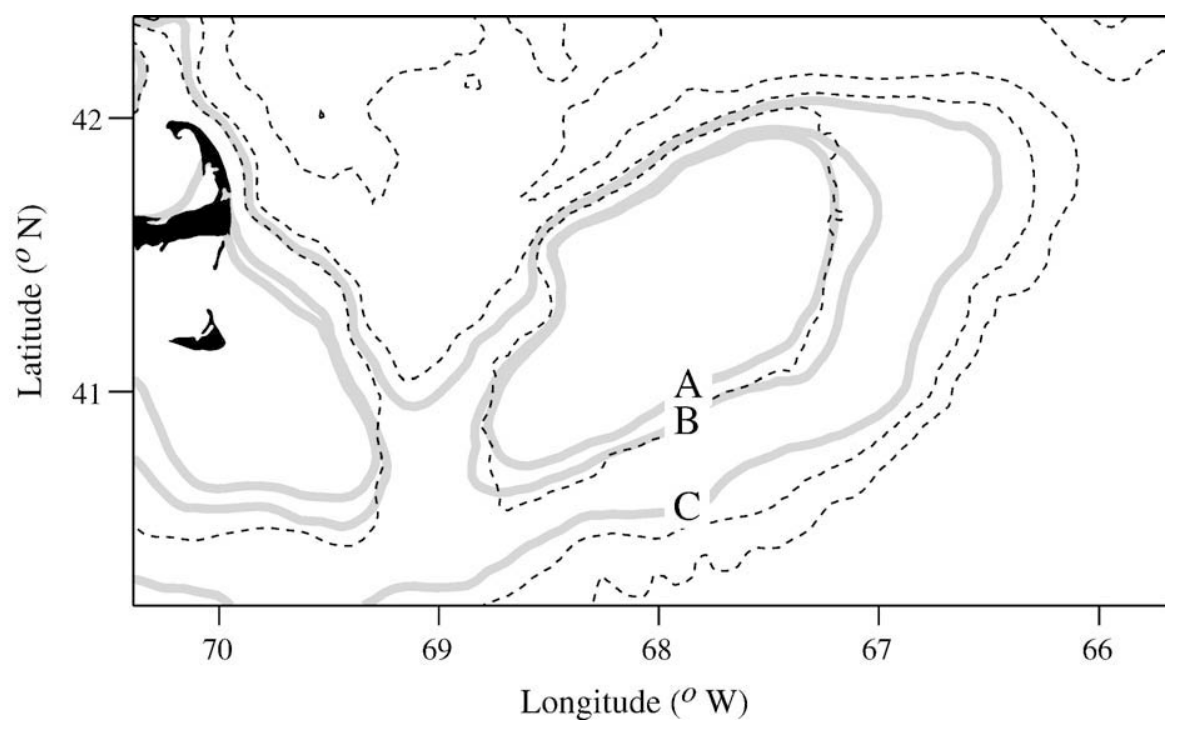

Fig. 10. Positions of the tidal mixing front (the mixed region is defined as an area in which the surface-bottom density (sigma-t) difference is less than 0.5 . A: Jul.Aug.; B: Sep.-Oct.; and C: Nov.-Dec. The 60-, 100-, and 200-m isobaths are shown. 

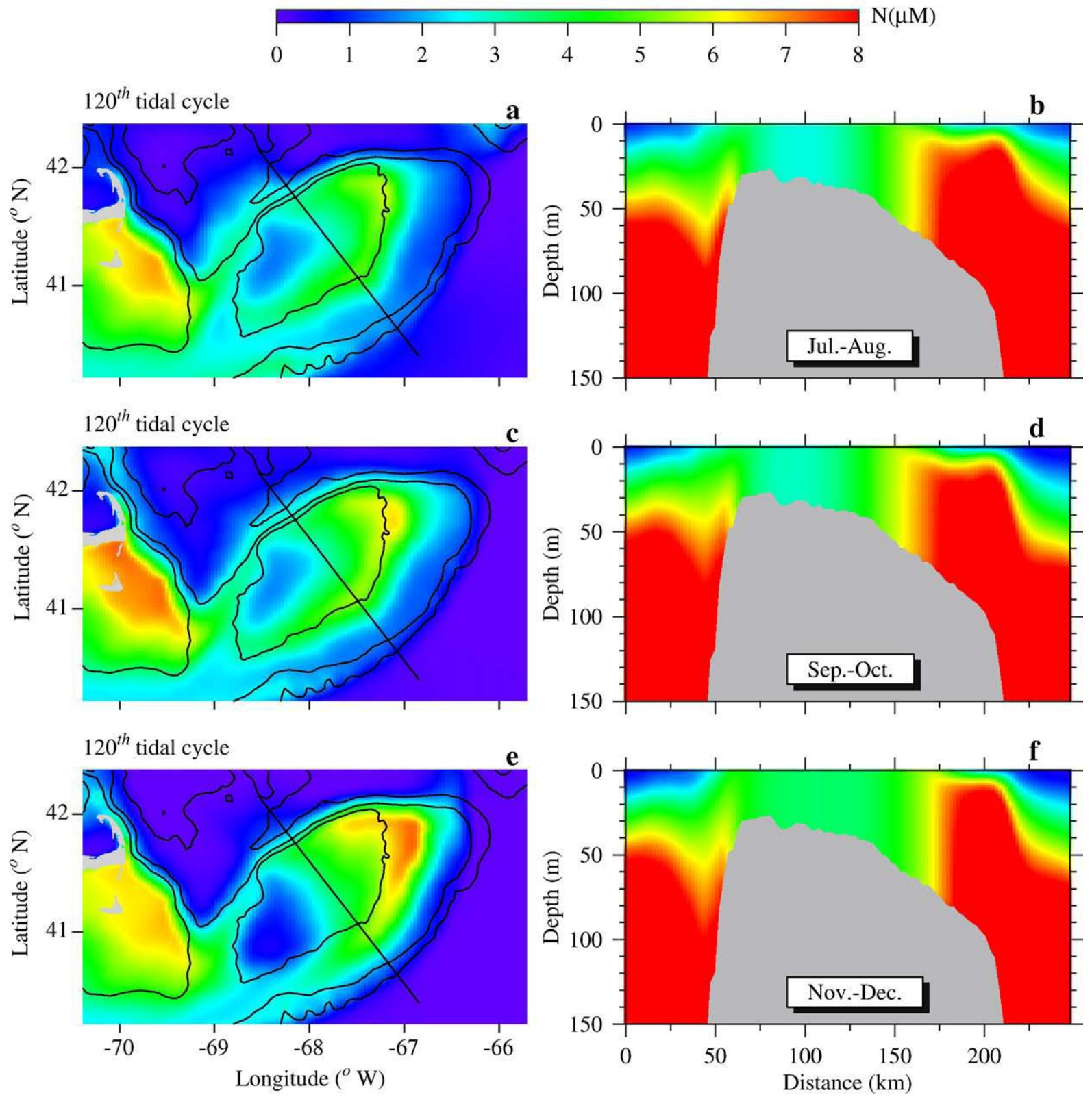

Fig. 11. Near-surface horizontal and cross-bank vertical distributions of tidally-averaged nutrient concentrations at the 120 th tidal cycle for the cases with JulyAugust (a-b), September-October (c-d), and November-December (e-f) bi-monthly averaged stratifications, respectively. The 60-, 100-, and 200-m isobaths are shown.

toward the shelf break and the stratification weakened (Fig. 10). Driven by the same $\mathrm{M}_{2}$ tidal forcing, the model showed that the nutrient flux onto GB varied significantly with the seasonal transition in water column stratification. In the July-August (summer) condition, the model displayed the donut-shaped feature of surface nutrient concentration around the tidal mixing front (Fig. 11a, b), as hypothesized based on field observations (Townsend and Pettigrew, 1997; Townsend et al., 2006) as well as bio-physical modeling results (Franks and Chen, 2001). Similar distributions were revealed in the September-October (fall) and NovemberDecember (winter) conditions, except that the patch of high nutrient concentration on the eastern portion of the Bank extends farther to the east towards the $80-\mathrm{m}$ isobath from the fall to the winter (Fig. 11c-f). The total mean concentrations of nitrate tracer within the $60-\mathrm{m}$ isobath were $3.86 \mu \mathrm{M}$ in summer, $4.05 \mu \mathrm{M}$ in fall and $3.40 \mu \mathrm{M}$ in winter (Table 3), with maximum seasonal values of $\sim 5.9 \mu \mathrm{M}, \sim 6.6 \mu \mathrm{M}$ and $\sim 7.4 \mu \mathrm{M}$, each located on the northeastern portions of the Bank. In the shallow crest area of the Bank, bounded by the $60-\mathrm{m}$ isobath, the tidally-induced nutrient recharge is greatest in the fall and weakest in the winter. This is consistent with the seasonal intensification and breakdown of the tidal mixing front, which is strongest in the summer, and weaker in the fall 
Table 3

Tidally-averaged concentrations of nutrients within the 60-m isobath on Georges Bank at the 120th tidal cycle for the listed experiments (units: $\mu \mathrm{M}$ )

\begin{tabular}{lllll}
\hline Month & Exp \#3 & Exp \#4a & Exp \#4b & Exp \#6 \\
\hline Jul.-Aug. & 3.86 & 3.88 & 4.07 & 4.46 \\
Sep.-Oct. & 4.05 & 4.03 & 4.62 & 2.61 \\
Nov.-Dec. & 3.40 & 4.24 & 6.78 & 5.81 \\
\hline
\end{tabular}

and winter. It should be noted that in the simulation forced only by tides, the nutrients pumped onto the Bank from the northeast flank is stronger in the winter than in the fall. However, since the maximum concentration patch shifts towards the shelf break with the off-Bank migration of the TMF, the nutrient flux into the top of the Bank in the winter is lower than in the fall.

\subsection{Experiment \#4}

For this experiment, we added the bi-monthly averaged wind stress to the model and repeated Exp. \#3 which allowed us to estimate the contribution of the wind stress to the seasonal variation in the nutrient flux to the top of GB. The model showed that the influence of the mean wind stress on the flux is very weak in the summer and fall, while it accounts for nearly a $24.7 \%$ increase in the winter (Table 3, Exp. \#4a) over the analogous simulation with no wind forcing. A reanalysis of 27 years of wind stress derived from the GoM MM5 model clearly shows that the wind on GB varies significantly with a time scale of 3-7 days, so that the monthly averaged wind stress is significantly smaller than the RMS variation. By taking the standard deviation of the bimonthly wind stress into account, the nutrient replenishment on the top of the Bank in the fall through winter is significantly increased, especially in the early winter where it increases by nearly 100\% (Table 3, Exp. \#4b).

\subsection{Experiment \#5}

The tidal pumping induced on-Bank nutrient flux depends on the initial vertical profile of nutrient concentration off the Bank, especially in the deeper flank region between $60 \mathrm{~m}$ and $100 \mathrm{~m}$ over the slope. An examination of monthly climatological fields of nutrients shows that the concentrations and distributions of nutrients in the GoM vary seasonally. We reran Exp. \#3 using alternate vertical profiles of nutrient concentrations representing low and high concentrations in waters deeper than $60 \mathrm{~m}$. We found that at the 40th tidal cycle, the average nitrate concentration inside the 60-m isobath over GB is about $1.71 \mu \mathrm{M}$ and $1.03 \mu \mathrm{M}$ for Type II (high) and Type III (low) initial profiles, respectively, compared to a value of $1.4 \mu \mathrm{M}$ for the Type I initial profile used in Exp. \#3.

\subsection{Experiment \#6}

This experiment was the same as Exp. \#4 except that we included a more realistic initial nutrient condition based on historical data. Those data (for nitrate) inside the 60-m isobath, compared with our idealized nutrient initial condition were $\sim 15 \%$ higher in July-August, $35 \%$ lower in September-October, and 37\% larger in November-December
(Table 3). The large differences detected in the fall and winter support our finding in Exp. \#5 that the nutrient refreshment over GB is significantly influenced by the nutrient field in the off-Bank waters in the GoM.

\section{Discussion}

Results from the numerical experiments support previous findings from both field and more idealized model experiments. For example, they support the earlier reports by Cura (1987) that diatoms are more dominant on the northern flank than on the southern flank and generally higher phytoplankton biomass is typically found on the northeast flank. Based on nutrient and Chl- $a$ measurements, Townsend et al. (2006) hypothesized that the nutrients over GB are drawn from the deeper waters around the Bank's edges to the northern flank where they are then advected by the residual circulation around the Bank to the southern flank, creating the "donutshaped" pattern of nutrients and phytoplankton production. Our experiments clearly show a major source of nutrients onto GB is on the northeast flank where the residual currents bifurcate and a donut-shaped distribution of nutrients forms due to the clockwise residual currents.

Chen and Beardsley (2002) summarized four physical mechanisms of cross-frontal water exchange on GB: 1) nonlinear tidal current interactions; 2) asymmetric tidal mixing; 3) variable winds; and 4) chaotic mixing. They suggested that "tidal pumping", the tide-induced Lagrangian upwelling, is the key physical process for transport of nutrients from deep water onto the Bank near the bottom (Chen and Beardsley, 1998). This mechanism was supported by a coupled physicalbiological experiment made by Franks and Chen (2001). With a simple Nutrient-Phytoplankton-Zooplankton (NPZ) model coupled with the Princeton Ocean Model (POM) and driven only by tides, they were able to reproduce the "donut-shaped" nutrient distribution around the tidal mixing front on GB. With better resolution of the complex bathymetry over the northern and northeastern flanks of GB, our model (FVCOM) experiments suggest that the "tidal pumping" varies significantly in space in this region, with a major source located near the northeast flank where the residual current bifurcates. This is consistent with the inter-model comparison results found by Tian and Chen (2006), who pointed out that the failure to resolve the rapid change of bathymetry on the northern flank of GB in a structured-grid model (like POM) can lead to an overestimate of the on-Bank water transport as well as an underestimate of the spatial variation of the tideinduced upwelling.

Using a long-term nutrient database including data from 1931 to $2005^{1}$, we computed monthly averaged (or "climatologic") values of nitrate concentration on the top of GB inside the $60-\mathrm{m}$ isobath (Fig. 12a). The nitrate concentrations are highest in February with a mean value of $6.5 \mu \mathrm{M}$, and decrease to $0.1 \mu \mathrm{M}$ from early spring to summer before recharging in the fall and early winter. In the months for which our experiments were conducted, the observed monthly-mean nitrate concentrations were 0.5 and $0.3 \mu \mathrm{M}$ in June and July,

\footnotetext{
1 The major data sources are the US GLOBEC NWA program, NODC and MESD, with additional data provided by Pierre Clement at Bedford Institution of Oceanography (Fisheries and Oceans Canada, 2006).
} 

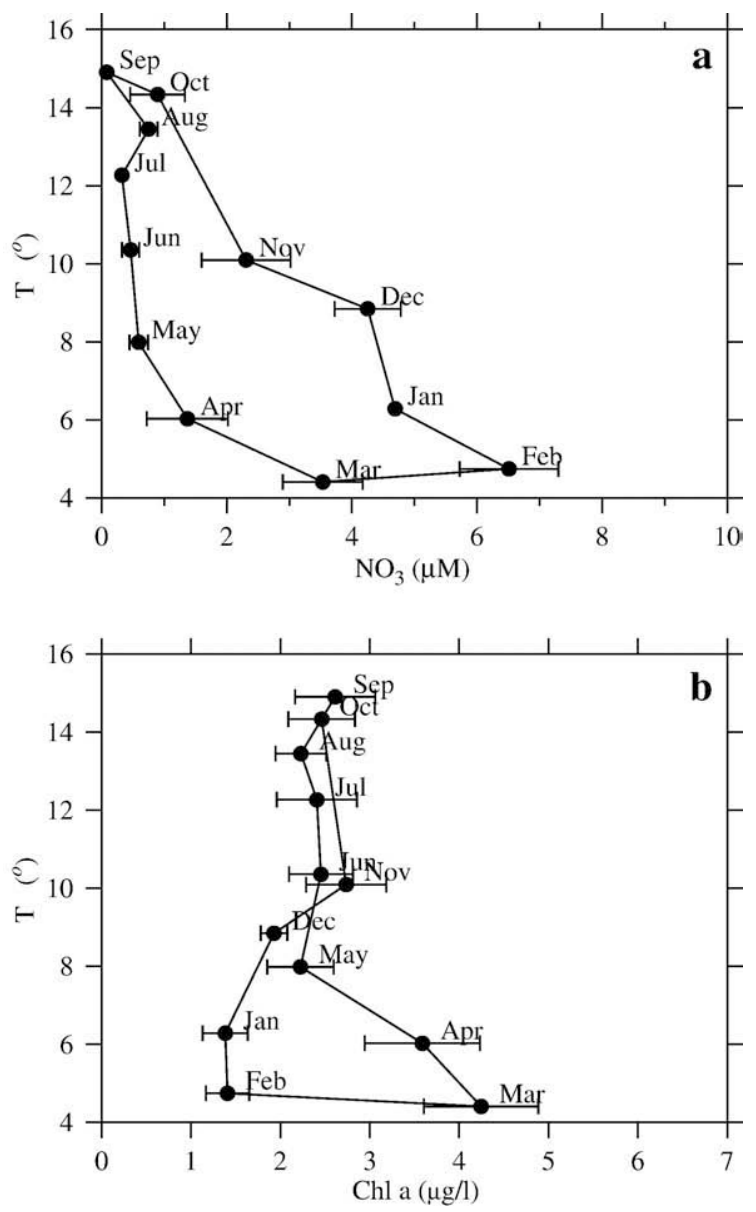

Fig. 12. Annual cycles of observed monthly averaged nitrate and chlorophyll concentrations versus temperature on the top of Georges Bank. Each dot represents the mean of the monthly averaged values computed for each year with sufficient data in that month, and the horizontal bar is the standard deviation of the mean. (The number of nutrient samples for January, July and September are not enough to calculate the standard deviations of the mean, so the horizontal bars for those months are omitted).

$0.7 \mu \mathrm{M}$ and $0.1 \mu \mathrm{M}$ in August and September, 0.9 and $2.3 \mu \mathrm{M}$ in October and November, and 4.3 and $4.7 \mu \mathrm{M}$ in December and January. This reconstructed seasonal pattern (Fig. 12a) is very similar to that reported by Pastuszak et al. (1982) based on single-year cruise data, suggesting that this structure represents a general seasonal pattern on GB. The large uncertainty shown in Fig. 12a is due to significant interannual variability. Despite such variability, the seasonal pattern remained little changed year to year. Without including biological processes, our model experiments suggest that the tidal pumpinginduced flux of nutrients onto GB can produce roughly a mean nutrient concentration on the top of GB of up to $\sim 3.86 \mu \mathrm{M}$ in summer and $\sim 4.05 \mu \mathrm{M}$ in fall. The modeled contribution from the monthly-mean wind stress is weak, but variable wind stress in the fall and winter can cause a large refreshment of nutrients on GB (Table 3). Compared with the data in Fig. 12a, the model-predicted values are significantly greater in summer and roughly the same in the fall and winter (when the effects of wind variability are included). This suggests, of course, that biological uptake is important in maintaining low nutrient levels on the top of GB during the summer, and is consistent with the seasonal variation of observed Chl- $a$ concentrations summarized in Fig. 12b.

Earlier flux rate estimates made by Loder et al. (1982) using observed temperatures gave a horizontal diffusion rate $\left(A_{\mathrm{h}}\right)$ of $\sim 150-380 \mathrm{~m}^{2} / \mathrm{s}$. They argued that, based on diffusive processes, new nutrients account for $20 \%-40 \%$ of the total nutrients on the Bank. With an estimated water column primary production rate of about $2 \mathrm{gC} / \mathrm{m}^{2} / \mathrm{d}$ from spring to later fall (Cohen et al., 1982) and assuming a Redfield ratio of $\mathrm{N}$ :C of $16: 106$, we estimate that a nutrient supply rate of $0.05-$ $0.12 \mu \mathrm{mol} \mathrm{N} / \mathrm{m}^{2} / \mathrm{s}$ is required to maintain a level of $20 \%-40 \%$ new nutrients on the Bank. Considering the temporal and spatial variations of a tidal mixing front resulting from the spring-neap tidal cycle, baroclinic eddies and near-bottom on-Bank flow, Loder and Platt (1985) suggested a total crossfrontal nutrient flux of $3.5 \times 10^{5} \mathrm{mg}$ at $\mathrm{N} \mathrm{s}^{-1}$ for the whole Bank area within the $60-\mathrm{m}$ isobath. Converting this value to an average rate over the area within the $60-\mathrm{m}$ isobath gives $0.025 \mu \mathrm{mol} \mathrm{N} / \mathrm{m}^{2} / \mathrm{s}$. Horne et al. (1989) used a skew flux method to estimate the depth-integrated cross-frontal nitrate flux onto GB; their estimated value is $12 \mathrm{mg}$ at $\mathrm{N} \mathrm{m}^{-1} \mathrm{~s}^{-1}$, which corresponds to an average rate of $\sim 0.34 \mu \mathrm{mol} \mathrm{N} / \mathrm{m}^{2} / \mathrm{s}$ by assuming the perimeter is $\sim 400 \mathrm{~km}$. Townsend and Pettigrew (1997) found that the nitrate supply rate onto GB varied significantly in space. They estimated depth-integrated flux of $\sim 2.9 \mathrm{mg}$ at $\mathrm{N} \mathrm{m}^{-1} \mathrm{~s}^{-1}$ on the northern flank, $0.3 \mathrm{mg}$ at $\mathrm{N} \mathrm{m}^{-1} \mathrm{~s}^{-1}$ on the eastern flank, $0.8 \mathrm{mg}$ at $\mathrm{N} \mathrm{m}^{-1} \mathrm{~s}^{-1}$ on the southern flank, and $0.3 \mathrm{mg}$ at $\mathrm{N} \mathrm{m}^{-1} \mathrm{~s}^{-1}$ on the western flank. Their area-averaged rate within the 60 -isobath was determined to be $\sim 0.034 \mu \mathrm{mol} \mathrm{N} / \mathrm{m}^{2} / \mathrm{s}$. Therefore, the area-average supply rate onto GB estimated from these field measurements is in the range $\sim 0.02-0.34 \mu \mathrm{mol} \mathrm{N} / \mathrm{m}^{2} / \mathrm{s}$. Our model results obtained for summer stratification give $\sim 0.03 \mu \mathrm{mol} \mathrm{N} / \mathrm{m}^{2} / \mathrm{s}$. This value is in agreement with that estimated by Townsend and Pettigrew (1997), who argued that the large value of $\sim 0.34 \mu \mathrm{mol} \mathrm{N} / \mathrm{m}^{2} / \mathrm{s}$ estimated by Horne et al. (1989) was too high and was unrealistic during summer on GB. Working from the estimate of Townsend and Pettigrew, findings from the present work suggest that tidal pumping is the primary process responsible for bringing nutrients onto GB in summer.

It should be noted again that because our modeling experiments focused on verifying and quantifying the role of tidal pumping, mean wind stress, and wind stress variability in supplying nutrients to GB using various initial conditions for hydrography and initial nutrient distribution, we did not include any biological processes in this study. Nonetheless, our results clearly show that biological processes are important in maintaining the observed low nutrient levels on GB in summer and perhaps can also indirectly contribute to the skew on-Bank nutrient flux by modifying the vertical and spatial distributions of the nutrients. Based on the tidal pumping idea proposed in our experiments, Ji et al. (in press) extended our experiments to include an NPZD biological model and simulated the seasonal variation of nutrients in the GoM/GB region. A discussion on the contribution of biological processes to the tidal pumping process is discussed in detail in their paper.

Our experiments show that tidal pumping is mainly dominated by advective processes with a secondary contribution from vertical and lateral diffusion. The lateral diffusion flux, 
even though it is very small, may still be over-counted in our experiments due to an overestimate of the lateral diffusion coefficient on GB. Based on his GB dye experiment results, Houghton (2002) estimated the lateral diffusion coefficient in the tidal mixing front to be $A_{\mathrm{h}} \sim 10-20 \mathrm{~m}^{2} / \mathrm{s}$, which is about one order of magnitude smaller than the value suggested by Loder et al. (1982). By simulating the observed spreading of the initial dye patch, Chen et al. (2008) found that the model converges to the observed dye behavior when the horizontal resolution was increased to $\sim 500 \mathrm{~m}$ on GB. With this resolution, the Smagorinsky eddy parameterization yields values of $A_{\mathrm{h}}$ the same order of magnitude as that estimated by Houghton (2002). The parameters used in our current experiments yield values of $A_{\mathrm{h}}$ in the same range as that suggested by Loder et al. (1982). A further study needs to be conducted with higher spatial resolution if one is interested in determining quantitatively the lateral diffusion nutrient flux onto GB.

\section{Conclusions}

The influence of tides and winds on nutrient transport onto GB is studied using a high-resolution nutrient tracer model driven by the GoM/GB FVCOM. The results show that tidal pumping, a result of the non-linear interaction of tidal currents over steep bottom topography, is the key process for the supply of nutrients to GB. The replenishment rate of nutrients to the Bank is also related to the seasonal variation in water column stratification, winds, and off-Bank sourcewater nutrient concentrations. In the homogenous case, the residual current bifurcates where the 40-m, 60-m and 100-m isobaths split along the northern flank. The tidal pumpinginduced on-Bank nutrient flux varies significantly in space, with a major source on the northeast flank where the isobaths and residual currents diverge. The clockwise residual current around GB is a dominant physical process that delivers nutrients downstream from the northeast flank to the southern flank. In summer, the winds are too light to influence significantly the on-Bank flux of nutrients, while tidal pumping dominates the flux to the mixed region of GB. Biological uptake depletes nutrients in the mixed region during the summer. In the fall through winter, particularly after the fall bloom, the recharge of nutrients to GB is mainly driven by the combined physical processes of tidal pumping and variable wind forcing. Seasonal variation of tidal pumping as a result of variable vertical stratification is significant, but within-season variability in stratification is insignificant. Rapid recharge in the fall and early winter is driven primarily by strong wind events, with winds becoming more important in late winter.

\section{Acknowledgments}

This research was supported by the U.S. GLOBEC Northwest Atlantic/Georges Bank Program through NSF grants (OCE-0234545; OCE-0227679, OCE0606928; OCE0712903; OCE0732084 and OCE0726851) and NOAA grant (NA16OP2323) for Changsheng Chen, NSF grant (OCE-0228943) to David W. Townsend, NSF grant (OCE-0236270) for Robert Houghton, the WHOI Smith Chair in Coastal Oceanography and NOAA grant (NA-17RJ1223) for Robert Beardsley, NOAA (grants NA04NMF4720332 and NA05NMF4721131) for Song $\mathrm{Hu}$ and Geoffrey Cowles, and NSF (grant OCE-0727033) and NOAA (grant NA17RJ1223) to Rubao Ji. The experiments were conducted using the Linux clusters in the Marine Ecosystem Dynamics Modeling Laboratory at the School of Marine Science and Technology, University of Massachusetts-Dartmouth, funded by the SMAST Fishery Program through NOAA grants NA04NMF4720332 and NA05NMF4721131. This paper is U.S. GLOBEC contribution number 596, SMAST Contribution Series number 08-0501, School for Marine Science and Technology, University of Massachusetts-Dartmouth and Lamont Doherty Earth Observatory contribution number 7149. The authors would like to thank two anonymous reviewers for their constructive suggestions on improving the quality of this paper.

\section{References}

Backus, R.H., 1987. Georges Bank. MIT Press, Cambridge, Mass. 593 pp.

Bigelow, H.B., 1927. Physical oceanography of the Gulf of Maine. Bull. U. S. Bur. Fish. 40, 511-1027.

Brink, K.H., et al., 2003. Properties of flow and pressure over Georges Bank as observed with near-surface drifters. J. Geophys. Res. 108, C118001. doi:101029/2001JC001019.

Brown, W., Moody, J., 1987. Tides. In: Backus, R.H. (Ed.), Georges Bank. MIT Press, Cambridge, Mass., pp. 100-107.

Butman, B., Beardsley, R.C., 1987. An introduction to the physical oceanography of Georges Bank. In: Backus, R.H. (Ed.), Georges Bank. MIT Press, Cambridge, Mass. 593 pp.

Butman, B., et al., 1982. Recent observations of the mean circulation on Georges Bank. J. Phys. Oceanogr. 12, 569-591.

Chen, C., Beardsley, R.C., 1998. Tidal mixing and cross-frontal particle exchange over a finite amplitude asymmetric bank: a model study with application to Georges Bank. J. Mar. Res. 56, 1163-1201.

Chen, C., Beardsley, R.C., 2002. Cross-frontal water exchange on Georges Bank: some results from an U.S. GLOBEC/Georges Bank Program Model Study. J. Oceanogr. 58, 403-420.

Chen, C., Beardsley, R.C., Franks, P.J.S., 2001. A three-dimensional prognostic model study of the ecosystem over Georges Bank and adjacent coastal regions, Part I, physical model. Deep Sea Res. II 48, 419-456.

Chen, C., et al., 1995. A numerical study of stratified tidal rectification over finite-amplitude banks, part II, Georges Bank. J. Phys. Oceanogr. 25, 2111-2118.

Chen, C., et al., 2003a. Model study of the cross-frontal water exchange on Georges Bank: a three-dimensional Lagrangian experiment. J. Geophys. Res. 108 (C5), 3142. doi:10.1029/2000JC000390.

Chen, C., et al., 2003b. An unstructured, finite-volume, three-dimensional, primitive equation ocean model: application to coastal ocean and estuaries. J. Atmos. Ocean. Technol. 20, 159-186.

Chen, C., et al., 2005. Using MM5 to hindcast the ocean surface forcing fields over the Gulf of Maine and Georges Bank region. J. Atmos. Ocean. Technol. 22 (2), 131-145.

Chen, C., et al., 2006. An unstructured grid, finite-volume coastal ocean model (FVCOM) system. Special Issue entitled "Advance in Computational Oceanography". Oceanography 19 (1), 78-89.

Chen, C., et al., 2007. A finite-volume numerical approach for coastal ocean circulation studies: comparison with finite difference models. J. Geophys. Res. 112, C03018. doi:10.1029/2006JC003485.

Chen, C., et al., 2008. A model-dye comparison experiment in the tidal mixing front zone on the southern flank of Georges Bank. J. Geophys. Res. 113, C02005. doi:10.1029/2007JC004106.

Cohen, E.B., et al., 1982. Energy budget of Georges Bank. Can. Spec. Publ. Fish. Aquat. Sci. 59, 95-107.

Cura, J.J., 1987. In: Backus, R.H. (Ed.), Phytoplankton in Georges Bank. MIT Press, Cambridge, Mass., pp. 213-218.

Dugdale, R.C., Georing, J.J., 1967. Uptake of new and regenerated forms of nitrogen in primary productivity. Limnol. Oceanogr. 12, 196-206.

Eppley, R.W., Peterson, B.J., 1979. Particulate organic matter flux and planktonic new production in the deep ocean. Nature 282, 677-680.

Fisheries and Oceans Canada, 2006. BioChem: database of biological and chemical oceangraphic data. http://www.meds-sdmmdfo-mpo.gc.ca/ biochem/Biochem_e.htm. Version 8 (2005).

Franks, P.S.J., Chen, C., 1996. Plankton production in tidal fronts: a model of Georges Bank in summer. J. Mar. Res. 54, 631-651. 
Franks, P.J.S., Chen, C., 2001. A three-dimensional prognostic model study of the ecosystem over Georges Bank and adjacent coastal regions, Part II: coupled biological and physical model. Deep Sea Res. II 48, 457-482.

Galperin, B., et al., 1988. A quasi-equilibrium turbulent energy model for geophysical flows. J. Atmos. Sci. 45, 55-62.

Greenberg, D.A., 1983. Modeling the mean barotropic circulation in the Bay of Fundy and the Gulf of Maine. J. Phys. Oceanogr. 13, 886-904.

Horne, E.P.W., et al., 1989. Nitrate supply and demand at the Georges Bank tidal front. Sci. Mar. 53, 145-158.

Houghton, R.W., 2002. Diapycnal flow through a tidal front: a dye tracer study on Georges Bank. J. Mar. Sys. 37, 31-46.

Houghton, R.W., Ho, C., 2001. Diapycnal flow through the Georges Bank tidal front: a dye tracer study. Geophys. Res. Lett. 28 (1), 33-36.

Ji, R., et al., 2006a. Spring bloom and associated lower trophic level food web dynamics on Georges Bank: 1-D and 2-D model studies. Deep Sea Res. II 53, 2656-2683.

Ji, R., et al., 2006b. The impact of Scotian Shelf Water "cross-over" on the plankton dynamics on Georges Bank: a three-dimensional experiment for the 1999 spring bloom. Deep Sea Res. II 53, 2684-2707.

$\mathrm{Ji}, \mathrm{R}$., et al., in press. Influence of local and external processes on the annual nitrogen cycle and primary productivity on Georges Bank: a 3-D biological-physical modeling study. J. Mar. Syst. doi:10.1016/j. jmarsys.2007.08.002.

Lewis, C.V.W., et al., 2001. Biological-physical modeling of meroplankton transport and settlement patterns on Georges Bank. Deep Sea Res. II 48, 137-158.

Limeburner, R., Beardsley, R.C., 1982. The seasonal hydrography and circulation over Nantucket Shoals. J. Mar. Res. 40, 371-406 Supplement.

Limeburner, R., Beardsley, R.C., 1996. Near-surface recirculation over Georges Bank. Deep-Sea Res. II 43, 1547-1574.

Loder, J.W., 1980. Topographic rectification of tidal currents on the sides of Georges Bank. J. Phys. Oceanogr. 10, 1399-1416.

Loder, J.W., Horne, E.P.W., 1991. Skew eddy fluxes as signatures of non-linear tidal current interactions, with application to Georges Bank. Atmos.Ocean. 29, 517-546.

Loder, J.W., Platt, T., 1985. Physical controls on phytoplankton production at tidal fronts. In: Gibbs, P.E. (Ed.), Proceedings of the Nineteenth European Marine Biology Symposium. Cambridge University Press, pp. 3-21.

Loder, J.W., et al., 1982. Horizontal exchange on central Georges Bank. Can. J. Fish. Aquat. Sci. 39, 1130-1137.

Lynch, D.R., Naimie, C.E., 1993. The M2 tide and its residual on the outer banks of the Gulf of Maine. J. Phys. Oceanogr. 23, 2222-2253.

Mellor, G.L., Yamada, T., 1982. Development of a turbulence closure model for geophysical fluid problems. Rev. Geophys. 20, 851-875.
Naimie, C.E., 1996. Georges Bank residual circulation during weak and strong stratification periods: prognostic numerical model results. J. Geophys. Res. 101, 6469-6486. doi:10.1029/95JC03698.

Naimie, C.E., et al., 1994. Seasonal variation of the three-dimensional residual circulation on Georges Bank. J. Geophys. Res. 99, 15967-15990. doi:10.1029/94JC01202.

Naimie, C.E., et al., 2001. On the geographic and seasonal patterns of the nearsurface circulation on Georges Bank-from real and simulated drifters. Deep Sea Res. II 48, 501-518.

O'Reilly, J.E., et al., 1987. Primary production. In: Backus, R.H. (Ed.), Georges Bank. MIT Press, Cambridge, Mass., pp. 220-233.

Pastuszak, M., et al., 1982. One year of nutrient distribution in the Georges Bank region in relation to hydrography. J. Mar. Res. 14, 525-542.

Pringle, J.M., Franks, P.J.S., 2001. Asymmetric mixing transport: a horizontal transport mechanism for sinking plankton and sediment in tidal flows. Limnol. Oceanogr. 46 (2), 381-391.

Riley, G.A., 1941. Plankton studies, IV. Georges Bank. Bull. Bingham Oceanogr. 7, 1-73.

Roworth, E., Signell, R.P., 2001. Construction of Digital Bathymetry for the Gulf of Maine. (See http://pubs.usgs.gov/of/1998/of98-801/bathy/index.htm/).

Smagorinksy, J., 1963. General circulation experiments with the primitive equations: I. The basic experiment. Mon. Weather Rev. 91, 99-164.

Tian, R., Chen, C., 2006. Influence of model geometrical fitting and turbulence parameterization on phytoplankton simulation in the Gulf of Maine. Deep Sea Res. II 53, 2808-2832.

Townsend, D.W., Pettigrew, N.R., 1997. Nitrogen limitation of secondary production on Georges Bank. J. Plankton Res. 19 (2), 221-235.

Townsend, D.W., Thomas, A.C., 2001. Winter-sprint transition of phytoplankton chlorophyll and inorganic nutrients on Georges Bank. Deep Sea Res. II 48, 199-214.

Townsend, D.W., Thomas, M., 2002. Springtime nutrient and phytoplankton dynamics on Georges Bank. Mar. Ecol. Progr. Ser. 228, 57-74.

Townsend, D.W., et al., 2006. Oceanography of the Northwest Atlantic Continental Shelf. In: Robinson, A.R., Brink, K.H. (Eds.), The Sea: The Global Coastal Ocean: Interdisciplinary Regional Studies and Syntheses. Harvard University Press, pp. 119-168.

Ullman, D.S., et al., 2003. The front on the northern flank of Georges Bank in spring: cross-frontal fluxes and mixing. J. Geophys. Res. 108, 8010. doi:10.1029/2002JC001328.

Walsh, J.J., et al., 1987. Nitrogen cycling on Georges Bank and the New York Shelf: a comparison between well-mixed and seasonally stratified waters. In: Backus, R.H. (Ed.), Georges Bank. MIT Press, Cambridge, Mass., pp. 234-246. 